\title{
O DEVONIANO NO ESTADO DO MATO GROSSO DO SUL, BRASIL: NOVA ÁREA DE DISTRIBUIÇÃO E PRESENÇA DE TÍPICA FAUNA MALVINOCÁFRICA
}

\author{
Sandro Marcelo Scheffler ${ }^{1}$ \\ Rafael Costa da Silva ${ }^{2}$ \\ Daniel Sedorko 3 \\ 10.18190/1980-8208/estudosgeologicos.v30n2p38-76 \\ ${ }^{1}$ Museu Nacional/UFRJ, Departamento de Geologia e Paleontologia, Laboratório de \\ Paleoinvertebrados - LAPIN, Horto Botânico do MN, prédio do DV, Parque Quinta da Boa \\ Vista, R. Gen. Herculano Gomes, 1340 - São Cristóvão, CEP 20940-040, Rio de Janeiro, RJ, \\ Brasil, schefflersm@mn.ufrj.br \\ ${ }^{2}$ Museu de Ciências da Terra, Serviço Geológico do Brasil - CPRM, Rio de Janeiro, RJ, Brasil, \\ rafael.costa@cprm.gov.br \\ ${ }^{3}$ Universidade Federal de Uberlândia, Laboratório de Paleontologia Estratigráfica, Campus \\ Monte Carmelo, MG, Brasil. sedorko@ufu.br
}

\section{RESUMO}

Estratos devonianos são amplamente conhecidos na borda leste da Bacia do Paraná, particularmente no estado do Paraná. No entanto, os estudos são ainda escassos na borda noroeste, especialmente no estado do Mato Grosso do Sul. Durante estudos realizados para este trabalho foram levantados cerca de 120 sítios geológicos e paleontológicos na região, tendo sido identificadas algumas discrepâncias nos mapas de distribuição das unidades do Devoniano (Grupo Campos Gerais/Chapada) no referido estado. Neste trabalho é apresentada uma revisão da distribuição dos estratos do Devoniano no Mato Grosso do Sul, bem como um levantamento dos trabalhos paleontológicos na região que abordaram a típica fauna malvinocáfrica (PragianoEmsiano inicial), com intuito de incrementar a discussão sobre a gêneses dos depósitos do Devoniano no estado. A presença desta fauna, aliada a outras evidências estratigráficas, corrobora a não compartimentalização da Bacia do Paraná para esta idade. É levantada a hipótese de um tectonismo concomitante à deposição da Formação Ponta Grossa (=Grupo Chapada II inferior), principalmente para o topo da unidade, sugerida pelo contexto progradacional seguido de um hiato deposicional durante o Emsiano médio ao final do Eifeliano na área. É possível que o Arco de Campo Grande somente tenha adquirido expressividade geomorfológica no Emsiano médio, o que seria refletido na ausência de estratos datados como Emsiano tardio/Eifeliano em áreas aflorantes no estado e diversas outras evidências.

Palavras-chave: Bacia do Paraná, Formação Ponta Grossa, Formação São Domingos, Domínio Malvinocáfrico, Arco de Campo Grande.

\begin{abstract}
Devonian strata are widely known for the eastern edge of the Paraná Basin, particularly in the state of Paraná. However, studies are still scarce on the northwestern border, especially in the state of Mato Grosso do Sul. During the studies, around 120 geological and paleontological sites in the region were identified, and some discrepancies were identified in the distribution maps of the Devonian units (Campos Gerais / Chapada Group) in that state. This paper presents a review on the Devonian strata distribution in Mato Grosso do Sul state, as well a survey of paleontological works in the region of occurrence of the climax Malvinokaffric fauna (Pragianearly Emsian) in order to increase the discussion about the genesis of Devonian deposits. This
\end{abstract}


fauna, combined with other stratigraphic evidences, corroborates a non-compartmentalization of the Paraná Basin for this age. The hypothesis of a tectonism concomitant with the deposition of the Ponta Grossa Formation (=lower Chapada II Group) is raised, mainly to the top of the unit, corroborated by a progradational context followed by a depositional hiatus during the middle Emsian at the end of the Eifelian in the area. It is possible that the Campo Grande Arch only acquired geomorphological expressiveness during the middle Emsian which would be attested by the absence of strata dated as late Emsian / Eifelian in croping areas in the state.

Keywords: Paraná Basin, Ponta Grossa Formation, São Domingos Formation, Malvinokaffric realm, Arch of Campo Grande.

\section{INTRODUÇÃO}

A paleofauna do Sistema Devoniano é de longa data estudada, principalmente nas camadas inferiores da sucessão devoniana no estado do Paraná (e.g. Derby, 1878; Clarke, 1913; Koslowsky, 1913; Lange, 1943, 1954; Caster, 1954a, b; Lange e Petri, 1967; Morsch, 1986; Ciguel, 1989; Bosetti, 1989; Kotzian e Marchioro, 1997; Leme et al., 2004; Leme, 2006; Scheffler e Fernandes, 2007a, b; Scheffler, 2007, 2015; Comminskey, 2011, Scheffler et al., 2013; dentre muitos outros), tendo sido alvo nos últimos anos de uma reavaliação sob a ótica da tafonomia e da estratigrafia de sequências (Simões et al., 2002, 2003; Rodrigues, 2002; Rodrigues et al., 2003; Ghilardi, 2004; Zabini, 2007; Zabini et al. 2010; Bosetti, 2004; Bosetti et al., 2010, 2011, 2012; Horodyski, 2010, 2014; Comminskey, 2016; Mori e Leme, 2016; Horodyski et al., 2018; Sedorko et al., 2018a, b, c, 2019).

Em contrapartida, para a borda Noroeste os trabalhos são menos abundantes, se concentrando principalmente na Chapada dos Guimarães, localidade onde o Devoniano é conhecido desde que Herbert Huntington Smith coletou os primeiros fósseis em 1883 (Smith, 1883), encaminhando para o Museu Nacional onde se procederam as identificações (Derby, 1890). Dentre estes trabalhos pioneiros também há a expedição de Peter Vogel na região de Lagoinha, entre 1887 e 1888 (Vogel, 1893), onde foram coletados fósseis posteriormente estudados por Ammon (1893).

No Mato Grosso do Sul, as rochas de idade devoniana são conhecidas desde a década de 1940, sendo pela primeira vez citados fósseis em trabalhos de Caster (1947a, b), mas poucos são os trabalhos de cunho taxonômico, que descreveram e ilustraram formalmente os macroinvertebrados. Foram identificados apenas dois trabalhos (Boucot e Caster, 1984; Carvalho et al., 1987) com esse enfoque, sendo os demais, simples citações da ocorrência das rochas e de fósseis em trabalhos preliminares, resumos ou trabalhos de mapeamento (e.g. Caster, 1947a, b; Almeida, 1948, 1954; Del'Arco et al., 1982; Souza Jr. et al., 1987; Amaral Filho et al., 1989). Os mapas geológicos ainda usados são o mapa do projeto Radam Brasil (Del'Arco et al., 1982), a carta ao milionésimo da CPRM (2004) e o mais recente mapa do estado do Mato Grosso do Sul, também publicado pela CPRM (Lacerda Filho et al., 2006).

Em vários trabalhos de campo realizados entre 2014 e 2017 foi possível observar algumas discrepâncias nas distribuições geológicas do Devoniano no estado em relação aos mapas geológicos. Portanto, o objetivo do presente trabalho é refinar a distribuição destes estratos, em especial da Formação Ponta Grossa e São Domingos, do Grupo Campos Gerais. Esta distribuição geológica será apresentada em mapas 1:100.000, feitos com base em levantamento de campo e bibliográfico, em cartas topográficas e imagens de satélites. 
Tem objetivo também discutir a gênese dos depósitos do Devoniano na porção noroeste da Bacia do Paraná, representadas pelos depósitos do Mato Grosso do Sul, estudados a partir de trabalhos de campos e do levantamento bibliográfico das informações paleontológicas do Devoniano no estado, apresentando os afloramentos e demonstrando que o Mato Grosso do Sul apresenta um diverso Domínio Malvinocáfrico clímax (sensu Bosetti et al., 2012).

\section{CONTEXTO GEOLÓGICO}

A Bacia Sedimentar do Paraná está situada no centro-leste da América do Sul, totalizando uma área que se aproxima dos
$1.600 .000 \mathrm{~km}^{2}$, dos quais $1.000 .000 \mathrm{~km}^{2}$ estão situados em território brasileiro (Petri e Fúlfaro, 1988; Schneider et al., 1974). A maior parte dos estados de São Paulo, Paraná e Santa Catarina (regiões central e ocidental) e Rio Grande do Sul (regiões norte, central e ocidental) e parte dos estados de Mato Grosso, Mato Grosso do Sul, Minas Gerais e Goiás estão localizados nesta bacia (Fig. 1). Seu registro litológico, envolvendo rochas sedimentares e vulcânicas, alcança espessuras máximas de cerca de 6.000 metros, registradas ao longo do seu depocentro coincidente com o leito do rio Paraná (Bergamaschi, 1999), sendo considerada uma típica bacia intracratônica (Milani e Ramos, 1998).

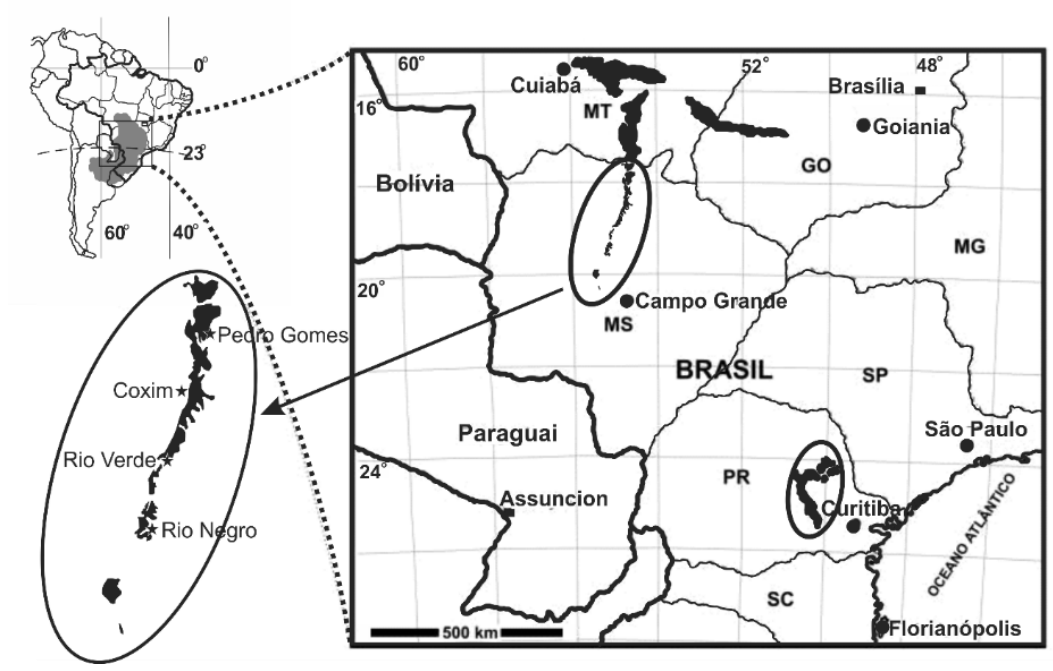

Figura 1 - Distribuição geográfica da área aflorante do Devoniano na borda leste e noroeste da Bacia do Paraná. Em destaque no canto esquerdo inferior a distribuição no estado do Mato Grosso do Sul (modificado de Borghi e Fernandes, 2001, com os dados deste artigo para o estado do Mato Grosso do Sul).

A Bacia do Paraná evoluiu entre o Neo-Ordoviciano e o Neocretáceo (Milani e Ramos, 1998) e seu registro é compreendido por um conjunto de supersequências (sensu Vail et al., 1977) distribuídas descontinuamente, que não ilustram toda esta extensão cronológica devido a lacunas entre as sequências e a hiatos intra-sequências (Bergamaschi, 1999).

Milani et al. (2007) dividiu a Bacia do Paraná em seis supersequências: Rio Ivaí (Grupo Rio Ivaí), Paraná (Grupo Paraná), Gondwana I (Grupos Itararé, Guatá e Passa Dois), Gondwana II (Formação Santa Maria), Gondwana III (formações Botucatu 
e Serra Geral) e Bauru (Grupo Bauru/Caiuá).

As rochas siluro-devonianas (Supersequência Paraná) afloram em faixas relativamente estreitas nas bordas leste e noroeste (Figs. 1, 2), sendo que na maior parte da área da bacia elas estão recobertas por rochas permo-carboníferas e mesozoicas (Petri e Fúlfaro, 1988). Segundo Northfleet et al. (1969) e Assine (1996), a Bacia do Paraná apresentava-se tectonicamente compartimentada no Devoniano. Dados de isópacas indicaram que naquele período a bacia possuía dois depocentros: um ao sul e outro ao norte. Estas áreas são consideradas como duas sub-bacias designadas, respectivamente, de Apucarana e Alto Garças. A Sub-bacia Apucarana ocuparia áreas hoje correspondentes aos estados de São Paulo, Paraná e Santa Catarina. A Sub-bacia Alto Garças ocuparia grande parte dos estados de Mato Grosso, Mato Grosso do Sul e do sudoeste de Goiás (Assine, 1996). Essa compartimentalização em duas sub-bacias estaria relacionada ao tectonismo sinsedimentar e, segundo Pereira e Bergamaschi (1996), pode ser estendida para momentos geológicos anteriores, como no Ordoviciano e Siluriano. Milani e Ramos (1998) também apresentaram mapa de isópacas, com a bacia sub-dividida em duas sub-bacias, separadadas pelos arcos de Campo Grande e Três Lagoas. Conforme Milani et al. (2007) a Superseqüência Paraná é um pacote caracterizado por uma notável uniformidade faciológica em toda a sua grande área de ocorrência.
O Devoniano da borda noroeste foi denominado de Grupo Chapada por Evans (1894), sendo comumente tratado na bibliografia também como Grupo Paraná ou Campos Gerais, por extensão da borda leste, composto por duas unidades: formações Furnas e Ponta Grossa, ou simplesmente fácies Furnas e Ponta Grossa (ver, por exemplo, Almeida 1948, 1954; Vieira, 1965 apud Melo, 1985; Oliveira e Muhlmann, 1965, 1967; Correa et al., 1976, 1979; Andrade e Camarço, 1978, 1980; Del'Arco et al., 1982; Araújo et al., 1982; CPRM, 2004; Lacerda Filho et al., 2006; Scheffler et al., 2010).

Andrade e Camarço (1978, 1980) sub-dividiram a Formação Ponta Grossa em Goiás e leste de Mato Grosso em três membros: inferior, médio e superior. Melo $(1985,1988)$ optou por usar o termo Grupo Chapada, em detrimento das denominações do Grupo Paraná, a saber formações Furnas e Ponta Grossa, subdividindo-o em Grupo Chapada I a IV e alegando que existe escasso conhecimento de correlação estratigráfica entre as duas bordas das bacias, motivo pelo qual Almeida (1948, 1954) cautelosamente já havia usado os termos fácies para as rochas "tipo" Furnas e Ponta Grossa, e portanto se justificaria a manutenção do termo "Chapada", juntamente com a questão da prioridade nomenclatural (Tabela 1). Esta nomenclatura tem sido atualmente usada na literatura (e.g. Grahn et al., 2000, 2002, 2013, 2016; Mendlowicz Mauller, 2007; Mauller et al., 2009). 
O DEVONIANO NO ESTADO DO MATO GROSSO DO SUL, BRASIL...

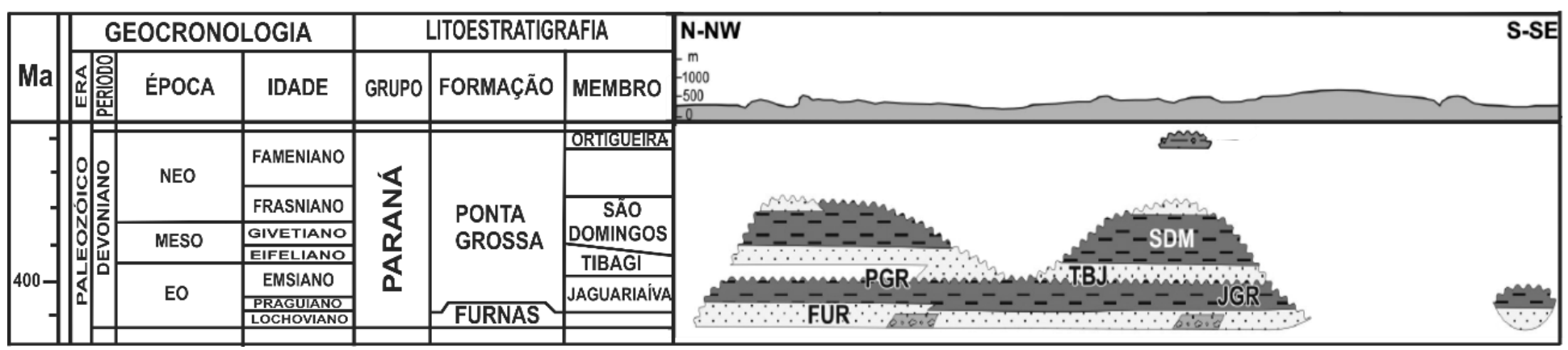

3 Figura 2 - Diagrama cronoestratigráfico do Grupo Paraná (modificado de Milani et al., 2007).

Tabela 1. Propostas de divisão estratigráficas da borda noroeste da Bacia do Paraná. * Consideramos o Grupo Chapada III, que é correlato ao Grupo Chapada II, mas ocorrendo mais a oeste, como equivalente do Membro Tibagi (sensu Grahn et al., 2013), porém bem mais espesso e não apenas restrito a base da Formação São Domingos como na borda leste.

\begin{tabular}{|c|c|c|c|c|c|}
\hline $\begin{array}{l}\text { Almeida } \\
(1948,1954) \\
\end{array}$ & $\begin{array}{l}\text { Andrade \& Camarço } \\
(1978,1980)\end{array}$ & $\begin{array}{l}\text { Melo }(1985,1988) \\
\text { e outros }\end{array}$ & $\begin{array}{l}\text { Arcabouço estratigráfico } \\
\text { De Sedorko et al. (2018a)* }\end{array}$ & Neste artigo & 9 \\
\hline $\begin{array}{l}\text { Fácies } \\
\text { Furnas }\end{array}$ & Formação Furnas & Grupo Chapada I & $\begin{array}{l}\text { Sequência Siluriana } \\
\text { Inferior }\end{array}$ & \multicolumn{2}{|c|}{ Formação Furnas } \\
\hline \multirow{4}{*}{$\begin{array}{l}\text { Fácies Ponta } \\
\text { Grossa }\end{array}$} & Membro Inferior & $\begin{array}{l}\text { Grupo inferior } \\
\text { Chapada II }\end{array}$ & $\begin{array}{l}\text { Sequência Siluro- } \\
\text { devoniana }\end{array}$ & $\begin{array}{l}\text { Formação } \\
\text { Ponta Grossa }\end{array}$ & $\begin{array}{l}\text { Praguiano - } \\
\text { Emsiano Inicial }\end{array}$ \\
\hline & & superior & Sequência Devoniana I & \multirow{3}{*}{$\begin{array}{l}\text { Formação } \\
\text { São } \\
\text { Domingos* }\end{array}$} & $\begin{array}{l}\text { Sub-unidades II e } \\
\text { III; Emsiano médio }\end{array}$ \\
\hline & Membro Médio & Grupo Chapada III & Sequência Devoniana II & & - Eifeliano \\
\hline & Membro Superior & Grupo Chapada IV & $\begin{array}{l}\text { Não registrada na borda } \\
\text { leste }\end{array}$ & & $\begin{array}{l}\text { Sub-unidade IV; } \\
\text { Givetiano- } \\
\text { Frasniano }\end{array}$ \\
\hline
\end{tabular}


Neste estudo optou-se por utilizar os termos empregados para a borda leste, pois após inúmeros trabalhos de bioestratigrafia com microfósseis, vários dos quais citados acima, mitigou-se o problema do escasso conhecimento de correlação estratigráfica. A Formação Ponta Grossa no estado do Paraná, dividida de forma clássica nos Membros Jaguariaíva, Tibagi e São Domingos (sensu Lange e Petri, 1967), também vem sendo dividida (ver Grahn, 1992; Bosetti et al., 2012; Grahn et al., 2013) em Formação Ponta Grossa, correlata ao Membro Jaguariaíva, e Formação São Domingos, correlata aos membros Tibagi e São Domingos.

As rochas aflorantes na borda noroeste apresentam, apesar de serem em geral de granulação mais grossa (especialmente em Goiás), perfeita correlação com a borda leste (e.g. Sedorko et al., 2018d), no qual a Formação Ponta Grossa (Grupo Chapada II inferior de Grahn et al., 2013) apresenta idade pragianaemsiana inicial separada do Devoniano mais novo por hiato deposicional nas duas bordas. Da mesma forma, a Formação São Domingos (Grupo Chapada II superior, III e IV) começou a ser depositada no início do Emsiano tardio nas duas bordas da bacia e apresenta uma superfície de máxima inundação, associada ao evento Káčak na passagem Eifeliano-Givetiano (ver Bosetti et al., 2011 para o estado do Paraná e Carbonaro e Ghilardi, 2016 e Grahn et al., 2016, para o estado de Goiás). Este intervalo é equivalente ao contato entre os grupos Chapada II superior e III, posicionados lateralmente, com o grupo Chapada IV. Aliado a isso, pode-se frisar a presença de cunha mais arenosa em posição estratigráfica similar que afina para o centro da bacia (Membro Tibagi e Grupo Chapada III), começando no Emsiano tardio, se bem que sub-representada na borda leste devido ao efeito erosivo do Arco de Ponta Grossa e a proximidade com o depocentro da bacia no intervalo, materializada no poço 2-TB-1PR (Assine, 1996).
Além disso, as rochas devonianas, ao menos no estado do Mato Grosso do Sul, apresentam conteúdo fossilífero similar, dentro da mesma bacia sedimentar, sugerindo ausência de compartimentalização no Devoniano Inferior (ver Sedorko et al., 2018d), não havendo justificativa paleontológica para a utilização de outra nomenclatura.

Portanto, os autores utilizam no presente trabalho para a borda noroeste a nomenclatura de Formação Furnas (=Grupo Chapada I), Formação Ponta Grossa (=Grupo Chapada II inferior) e Formação São Domingos (mantendo a sub-divisão litológica em unidades II superior, III e IV), estendendo o Grupo Campos Gerais para toda a bacia.

\section{PALEONTOLOGIA DO MATO GROSSO DO SUL: ESTADO DA ARTE}

Apesar da Formação Ponta Grossa ser muito rica em fósseis de invertebrados marinhos, no estado do Mato Grosso do Sul poucas são as referências a estes grupos. Historicamente, quatro expedições de cunho paleontológico foram realizadas nos mais de $300 \mathrm{~km}$ de rochas aflorantes: 1) em 1938 a equipe da antiga Divisão de Geologia e Mineralogia (D.G.M.), formada por Alberto I. Erichsen e A. Lofgreen parecem serem os primeiros a identificar a extensão do Devoniano para o atual território do Mato Grosso do Sul; 2) em 1941 outra equipe da D.G.M. na Expedição Anibal Bastos (Anibal A. Bastos, Alberto I. Erichsen e Llewellyn Igor Price) identificou fósseis devonianos no Ribeirão dos Cavalos, na rodovia Cuiabá-Campo Grande, entre os Rios Piquiri e Taquari; 3) em julho a agosto de 1947, pesquisadores da Universidade de São Paulo (Kenneth Caster, Setembrino Petri, Octávio Barbosa) e da Divisão de Geologia e Mineralogia do Brasil (Fernando Flávio Marques de Almeida) coletaram fósseis também no Ribeirão dos Cavalos e no Município de Rio Verde de Mato Grosso, pela primeira vez identificando a extensão das rochas 
devonianas tão para o sul do estado do Mato Grosso; 4) na década de 1980, quando em duas coletas da Expedição Orville Adalbert Derby, uma em fevereiro de 1985 (Werceny Siqueira e José H. G. de Mello) e outra em outubro de 1986 (A. J. Boucot, N. C. Azambuja Filho, L. P. Quadros e J. H. G. de Mello), foram revisitados poucos afloramentos, apenas em Rio Verde de Mato Grosso. Recentemente, depois de décadas, houve novos esforços de campo coordenados por pesquisadores de projetos da Universidade Estadual do Rio de Janeiro e da Universidade de São Carlos.

Como resultado das expedições de 1938, Erichsen e Lofgreen (1940) citaram a ocorrência de "Rochas do Devoniano, identificadas paleontologicamente" até a proximidades de Brioso, na estrada CuiabáCampo Grande. Conforme Melo (1985) esta localidade deveria se situar a sudeste da cidade de Rio Verde de Mato Grosso. É difícil dizer se Erichsen e Lofgreen (1940) estavam se referindo a esta localidade, uma vez que em nenhum momento os autores descreveram o trajeto percorrido abaixo do Rio São Lourenço, na Serra de São Vicente, a sudeste de Cuiabá.

Moraes Rego (1940, p. 145 e 146) argumentou que o Devoniano também deveria ocorrer rumo ao sul da Chapada, mas a extensão da "série" da Chapada dependeria de verificação e de um melhor conhecimento da estrutura do trecho intermediário da escarpa, entre as regiões de Cuiabá e Aquidauana. Já em 1943, Anibal A. Bastos e A. I. Erichsen comentaram a ocorrência de afloramentos do Devoniano até $60 \mathrm{~km}$ ao sul de Herculânea (atual Coxim), possivelmente constatado na já citada expedição Anibal A. Bastos, onde L. Price coletou os primeiros fósseis no Devoniano do Mato Grosso do Sul (Caster, 1947a; comunicação verbal de L. Price, vide Oliveira e Leonardos, 1978, p. 323, já referida na primeira edição de 1943).

No entanto, esta distribuição meridional até Rio Verde de Mato Grosso só foi confirmada por Caster (1947a), que citou a presença de "spirifers", em localidade situada na subida do Rio Verde para Campo Grande (situado possivelmente entre os pontos MS24 e MS25 deste trabalho; fig. 11), município de Rio Verde de Mato Grosso. Este afloramento foi indicado no Mapa do RADAM-BRASIL como localidade fossilífera número 8 (Del'Arco et al., 1982). Sem citar outras localidades, Del'Arco et al. (1982) também comentaram que na folha SE. 21 são comuns intercalações subordinadas de folhelhos fossilíferos. Caster (1947a, p. 127) também citou “(...) uma esplêndida fauna, nova e grande, no Ribeirão dos Cavalos (onde Price encontrou a Lingula)", durante a expedição Anibal Bastos. Esta fauna teria claras afinidades com a Bolívia, representados “(...) pelo gênero Stricklandia e pelecípodos concentricamente ornamentados e muito grandes". Esta localidade não foi localizada no presente trabalho apesar de se situar ao sul de Rondonópolis, provavelmente no Mato Grosso do Sul, no divisor entre os rios Piquiri e Taquari, conforme Almeida (1948).

Caster (1947a) argumentou que quanto à extensão superficial do Devoniano na borda noroeste da bacia, seu reconhecimento teria sido mais do que duplicado pela excursão de 1947, e na opinião de Almeida (1948), os afloramentos dissociados que constavam nos mapas geológicos de então deveriam ser conectados, tanto no Mato Grosso, como na região das bacias hidrográficas do alto Taquari e Piquiri, mais a sudeste em Mato Grosso do Sul, opinião compartilhada por Caster (1952), cuja geologia era então conhecida apenas ao longo da rodovia Cuiabá - Campo Grande.

Esta extensão meridional da Formação Ponta Grossa teria sido reconhecida pelo menos até os arredores do então povoado de Rio Verde, no atual estado de Mato Grosso do Sul, fato também lembrado por K. E. Caster (nota de rodapé em Caster e Mendes, 1952) que comentaram a presença de fósseis na expedição de 1947. 
Caster (1947b) confirmou esta ampliação da distribuição do Devoniano nos antigos limites geográficos do estado do Mato Grosso, e citou uma nova fauna rica, que incluía elementos andinos, na área mais ao sul de ocorrência das rochas do Devoniano, onde hoje é o estado do Mato Grosso do Sul, provavelmente no Ribeirão dos Cavalos, como comentado acima.

Almeida (1948) publicou os resultados geológicos da expedição acima mencionada, que realizou em companhia de Kenneth E. Caster, e mencionou novamente a coleta de 20 fósseis de invertebrados no divisor entre o Rio Piquiri e Taquari, no Ribeirão dos Cavalos, onde L. Price na expedição Anibal Bastos, do DGM, em 1941, coletou fósseis do Devoniano. Almeida (1948) também falou da coleta de Spirifer uma légua a sudeste do povoado de Rio Verde, apresentando um mapa geológico onde a "Série Paraná" (Grupo Campos Gerais/Chapada) se estenderia bem ao sul desta localidade e um perfil geológico desta região, onde ocorre o "folhelho e arenito Ponta Grossa". Almeida (1954, p. 44) também fez menção à presumível “(...) ocorrência dos horizontes mais elevados da série também nos vales dos rios Itiquira, Piquiri e Taquari”. O Rio Piquiri se situa no extremo norte do estado Mato Grosso do Sul e o rio Taquari atravessa os municípios de Pedro Gomes e Coxim, onde foi possível levantar dezenas de afloramentos apresentados no presente trabalho (figs. 6, 7, 8 e 9). Apesar destes trabalhos, Lange (1967) em mapa geológico afirma que os folhelhos do Devoniano, atribuídos a Formação Ponta Grossa, chegam apenas até ao norte do município de Coxim.

Gonçalves e Schneider (1970, apud Melo, 1985) apresentaram os resultados obtidos com o mapeamento fotogeológico e de semidetalhe no centroleste de Mato Grosso. A área de estudo estendia-se desde Aragarças até a Chapada dos Guimarães e, rumo ao sul, para além de Rondonópolis, até a altura da localidade Pedro Gomes. Os mapas, elaborados nas escalas 1:100.000 e 1:250.000, atestam a ampla distribuição regional das rochas de idade devoniana (designadas formações Furnas e Ponta Grossa) a oeste, em uma faixa de orientação norte-sul e largura variável em decorrência das condições estruturais, a qual se estende desde a Chapada dos Guimaraes até o extremo sul da área.

O Projeto Bodoquena (Corrêa et al., 1976, 1979) também citou a ocorrência da Formação Ponta Grossa no Mato Grosso do Sul como restrita às folhas Serra de Maracaju e Coxim, através de uma estreita faixa de direção NNE. Neste trabalho, os autores ampliaram seu limite meridional até a oeste da cidade de Rochedo, ao longo do rio Taboco, e seu prolongamento para norte ultrapassaria os limites setentrionais da área do projeto, já na altura da cidade de Pedro Gomes.

O projeto Radam Brasil (Del'Arco et al., 1982; Araújo et al., 1982), nas folhas de Corumbá e Campo Grande, mantém esta distribuição das rochas devonianas, no entanto nos mapas posteriores elaborados pela CPRM (2004) e Lacerda Filho et al. (2006) duas outras pequenas manchas são mapeadas, à norte e nordeste do município de Aquidauana, como a ocorrência mais meridional da Formação Ponta Grossa no estado.

Boucot e Caster (1984) identificaram e descreveram os braquiópodes Scaphiocoelia cf. S. boliviensis e Australocoelia?, ambos encontrados por Caster, na expedição de 1947 na Serra da Boa Sentença, município de Rio Verde de Mato Grosso, podendo demonstrar que existia na época uma franca ligação marinha com a Bolívia, diretamente com esta ou via o Paraguai.

Carvalho et al. (1987) citaram as duas coletas realizadas em 1985 e 1986, dentro do âmbito da Expedição Orville Derby, patrocinada pelo Centro de Pesquisas e Desenvolvimento Leopoldo A. Miguez de Mello (CENPES/PETROBRÀS):

"nos arredores da cidade de Rio Verde de Mato Grosso, MS, junto ao acostamento do lado SW da BR163 (Campo Grande - Cuiabá), em um 
sítio de exploração de argila foram obtidos os fósseis descritos aqui...”.

Esta talvez deva ser uma área de extração de argila, atualmente desativada, que se situava próximo ao ponto MS24 (fig. 11), posicionado ao longo do acostamento da dita rodovia. Carvalho et al. (1987) descreveram trilobitas, identificando-os como Calmonia subseciva, Burmeisteria sp. e dois espécimes de trilobitas indeterminados.

Melo (1988) também citou a ocorrência de formas malvinocáfricas perto de Rio Verde de Mato Grosso, apresentando em sua listagem de fósseis que compõem o mapa paleobiogeográfico do Emsiano a presença de Bivalvia indet., Scaphiocoelia e Australocoelia? (provavelmente se referindo ao trabalho de Boucot e Caster, 1984) e Australospirifer? [tipificado por $A$ ? laurosodreanus (Katzer, 1903)] e do mapa do Emsiano tardio/Eifeliano a presença de Calmonia, Burmeisteria (trilobitas, provavelmente, citados com base em Carvalho et al., 1987), restos indeterminados de plantas, Encrinaster e Orbiculoidea. Ambas listas se referem a coletas realizadas na Serra da Boa Sentença (possivelmente na área do afloramento MS24 ou entre MS24 e MS25 deste trabalho).

No entanto, as citações mais abundantes na literatura são de microfósseis, devido à preocupação na datação e correlação destas rochas com os demais pontos da bacia e de outras bacias paleozoicas brasileiras e estrangeiras. Lange (1967) e Daemon (1967) citaram a presença de microfósseis de quitinozoários, acritarcas e esporos em dois poços situados no atual território do Mato Grosso do Sul: um em Três Lagoas, chamado de TLst-1MT; e outro no Município de Ribas de Rio Pardo, chamado de RPst-1-MT.

Oliveira (1997), em seu trabalho de Doutorado focando a palinologia da Bacia do Paraná, citou quatro afloramentos no município de Rio Verde de Mato Grosso: RV-1-MS - pedreira na cidade, próximo ao hospital do município (possivelmente a pedreira Fênix, MS 29 do presente trabalho); RV-2-MS - pedreira Barreiro Figueira, $3 \mathrm{~km}$ a leste da cidade (MS30 do presente trabalho); RV-3-MS - rodovia BR163, trecho Rio Verde-Campo Grande, $\mathrm{km}$ 1,5 (MS24 do presente trabalho); e RV4-MS - rodovia BR 163, dentro da cidade (afloramento não foi mais encontrado, possivelmente citado em Carvalho et al., 1987). O terceiro afloramento se mostrou estéril para acritarcas e os outros três apresentaram associações que indicaram idade emsiana.

Grahn et al. (2000) citaram um afloramento contendo o quitinozoário Ramochitina magnífica, que indica idade pragiana. Conforme os autores este afloramento, denominado de Felix (sic) Quarry, é localmente conhecido como Barreiro da Prefeitura e está situado dentro da cidade de Rio Verde de Mato Grosso, próximo a BR 163 (afloramento MS29 deste trabalho, conhecido como Barreiro da Pedreira Fênix). Conforme Aguiar (2004) e Mendlowicz Mauller (2007) o furo de sondagem Paleosul-02-RV-MS, localizado no município de Rio Verde de Mato Grosso (18 $55^{\prime} 31,7^{\prime}, \mathrm{S}$ e $\left.54^{\circ} 50^{\prime} 21,1^{\prime}, \mathrm{W}\right)$, possui $100,7 \mathrm{~m}$ de profundidade. Devido à ausência do datum as coordenadas acima se situam entre a pedreira Fênix e o barreiro da Figueira; no entanto de acordo com o mapa apresentado por Aguiar (2004), o poço foi perfurado em posição coincidente ao da pedreira Fênix (MS 29 deste trabalho), informação confirmada por Egberto Pereira (comunicação pessoal, 2016). Este furo foi executado pelo Projeto Paleosul, coordenado por Egberto Pereira da Faculdade de Geologia da UERJ, com o apoio do programa Ctpetro/Finep/Profex (Petrobrás). O intervalo de 12 metros superior do poço representaria uma importante superfície de inundação na porção norte da bacia, para o intervalo eodevoniano (Aguiar, 2004). Este intervalo parece estar preservado justamente abaixo dos tempestitos da mina MS29, que poderiam funcionar como armadilhas para 
gás e óleo gerados nos folhelhos subjacentes (Sedorko et al., 2016).

Aguiar (2004) e Pereira et al. (2007) colocaram o limite entre as formações Furnas e Ponta Grossa justamente abaixo do nível de conglomerados do poço Paleosul02-RV-MS, similar ao que Andrade e Camarço (1980, p. 2.831) havia feito em Goiás, que, dividindo a Formação Ponta Grossa em três membros, citaram que " $\mathrm{O}$ membro inferior inicia-se com conglomerado basal, composto por seixos e matacões de quartzo, quartzito e ocasionalmente xisto...". Aguiar (2004) e Pereira et al. (2007) citaram diversas icnofácies a partir da análise deste poço e do afloramento aqui referido como MS29.

Grahn et al. (2002) estudando o poço Well 2-RP-1-MS (20 25' 17.1" S, 53 52' 22.1" $\mathrm{W}$; possivelmente o mesmo poço RPst-1-MT, que mudou de nome após a emancipação do estado) confirmou os achados de Lange (1967), que havia encontrado quitinozoários de idade givetiana inicial, citando também a presença de um arenito abaixo de idade eifeliana.

Conforme Mendlowicz Mauller (2007) o furo de Sondagem Paleosul-RV02-MS possui uma associação de miósporos, com formas semelhantes às formas identificadas na Seção Jaciara. Este furo de sondagem seria correspondente ao intervalo D2 de Daemon et al. (1967), à assembleia 2 de Dino (1999) e Dictyotriletes emsiensis (EMS) de Melo e Loboziak (2003). As biozonas de miósporos e a assembleia de acritarcos encontrados indicam uma idade Neopragiana a Eoemsiana. Também foram identificados acritarcos e prasinófitas, assim como os miósporos do Devoniano e retrabalhados do Siluriano. A associação encontra-se pouco diversificada e mal preservada (Mendlowicz Mauller, 2007; Mendlowicz Mauller et al., 2009).

Grahn et al. (2010) também citaram o afloramento chamado de Felix Quarry (MS 29 deste trabalho - Pedreira Fênix), posicionando-o no Pragiano tardio-
Emsiano inicial, assim como o poço Paleosul-02-RV-MT.

Através de projeto do $\mathrm{CNPq}$ (474952/2013-4), chamada Universal de 2013, diversos levantamentos de campo foram coordenados pelo Museu Nacional/UFRJ, em parceria com diversas instituições de pesquisa do país, que levaram ao mapeamento de inúmeros novos afloramentos apresentados neste artigo. Destes resultaram alguns resumos preliminares que serão brevemente comentados.

Scheffler e Silva (2014) escreveram sobre a ocorrência de diversa fauna malvinocáfrica (Devoniano Inferior) no estado do Mato Grosso do Sul, citando mais de dez afloramentos fossilíferos e identificando preliminarmente uma típica associação malvinocáfrica, apresentando bivalves, braquiópodes, tentaculitídeos, trilobitas e gastrópodes.

Silva et al. (2014), citaram 17 sítios paleontológicos com ocorrências de icnofósseis, concentrados entre os municípios Rio Negro, Rio Verde de Mato Grosso e Coxim (MS), identificando 15 icnogêneros. Já em Scheffler e Silva (2015a, b) o número de afloramentos da Formação Ponta Grossa subiu para 67, apresentando grande diversidade de macroinvertebrados e icnofósseis nos municípios de Rio Negro, Rio Verde de Mato Grosso, Coxim e Pedro Gomes.

Silva e Scheffler $(2015 a, b)$ citaram a ocorrência de 49 sítios paleontológicos com icnofósseis, concentrados nos municípios Rio Negro, Rio Verde de Mato Grosso, Coxim e Pedro Gomes. Foram ampliados os icnotáxons reconhecidos para 30. Bosetti et al. (2015) em um trabalho de tafonomia e taxonomia do afloramento MS14, em Rio Negro, identificaram 29 táxons. Em uma análise de icnofábrica, Sedorko et al. (2016) identificaram 14 icnotáxons no afloramento MS29 (pedreira Fênix)

Scheffler et al. (2015) descreveram a primeira ocorrência de espícula de esponja de idade devoniana na bacia. Trata-se de espículas de esponjas Hexactinellida, 
preservadas em concreções em afloramento do Rio Taquari, em Coxim (MS). Ferreira e Scheffler (2015), Silva et al. (2016, 2017, 2018) identificaram quatro espécies de discinideos distribuídos em 15 afloramentos. Scheffler (2016) realizou a primeira descrição de crinoides para o estado. Ghilardi et al. (2016) identificaram Calmonia sp, Burmeisteria sp. e Metacryphaeus sp., além de vários outros fragmentos de calmoniideos.

Em estudos de palinofácies, Carvalho et al. (2016) e Trindade et al. (2016, 2017) em pedreiras no município de Rio Verde (MS 26 e MS 27) identificaram partículas orgânicas amorfas, fitoclastos e palinomorfos. Gonçalves et al. (2018) citaram o gênero de escolecodonte Paulinites para a borda noroeste, além de descrever algumas novas formas de escolecodontes para o Devoniano da Bacia do Paraná, com base em conteúdo de lâminas palinológicas. Sedorko et al. (2018e) teceram considerações sobre uma forte associação entre a icnofábrica Chondrites-Zoophycos e plantas terrestres em afloramento do Rio Taquari, Coxim.

Alguns outros trabalhos foram realizados com macrofósseis no estado, como: Benini et al. (2016) que comentaram sobre a ocorrência de Orbiculoidea citando apenas a cidade de Rio Verde, sem apresentar uma descrição do material; Furtado et al. (2016) que descreveram uma possível interação e epibiose em orbiculoides do Devoniano do Município de Rio Verde, sem especificar a localidade,.

Outros artigos também abordaram a região, como Becker-Kerber et al. (2017) que realizaram um estudo sobre a fossildiagênese de fósseis em concreções da região do municipio de Rio Verde do Mato Grosso, citando a presença de orbiculóides, lingulídeos, Rhynchonellata e Strophomenata, assim como calmoniideos. Por fim, Sedorko et al. (2018d) utilizaram icnofósseis e uma abordagem tafonômica para fornecer interpretações paleoambientais de seções regressivas na região, discutindo as semelhanças com seções coevas da borda leste da bacia.

Pelo levantamento acima fica clara a carência de estudos com os fósseis do Devoniano no Mato Grosso do Sul, que representava a área de maior paleolatitude, hoje aflorante, do mar Devoniano da borda noroeste da Bacia do Paraná (ver Isaacson, 1981, 1996; Isaacson e Sablock, 1990; Isaacson e Martinez, 1994; Torsvik \& Cocks 2013).

\section{A NOVA DISTRIBUIÇÃO DA FORMAÇÃO PONTA GROSSA NO ESTADO DO MATO GROSSO DO SUL}

Através de extensos trabalhos de campo, que ampliaram o número de afloramentos conhecidos do Devoniano no Mato Grosso do Sul para mais de 70 (anexo 1), foi observada uma série de incongruências nos mapeamentos geológicos correntes (Corrêa et al., 1976, 1979; Araújo et al., 1982; CPRM, 2004; Lacerda Filho et al., 2006), mostrando que as rochas do Devoniano (excluindo a Formação Furnas) afloram em uma área menor do que aquela reconhecida atualmente. Isso é esperado em se tratando de mapeamentos de grande escala (1:1.000.000), como é o caso dos mapas geológicos do estado. A maioria dos equívocos deve-se a três fatores principais, especialmente relacionados à sua distribuição na região sul: 1) em algumas áreas, como em Taboco, a Formação Aquidauana é representada por um conglomerado com grandes intraclastos da Formação Ponta Grossa, frequentemente originando um solo típico das áreas de ocorrência desta última umidade geológica; 2) o topo local da Formação Ponta Grossa, principalmente na região entre Rio Negro e Rio Verde, é formado por arenitos finos a grossos, mal selecionados, amarelados a avermelhados, localmente apresentando estratificações cruzadas, que podem ser confundidos com arenitos da Formação Furnas ou da Formação Aquidauana (Figs. 3, 4 e 5); 3) a base da Formação Aquidauana 
entre Rio Negro e Rio Verde é formada por aproximadamente 10 metros de arenito grosso, mal selecionado e sub-arredondado, com grandes estratificações cruzadas, que pode ser confundido com o topo regional da Formação Ponta Grossa ou até mesmo com a Formação Furnas.

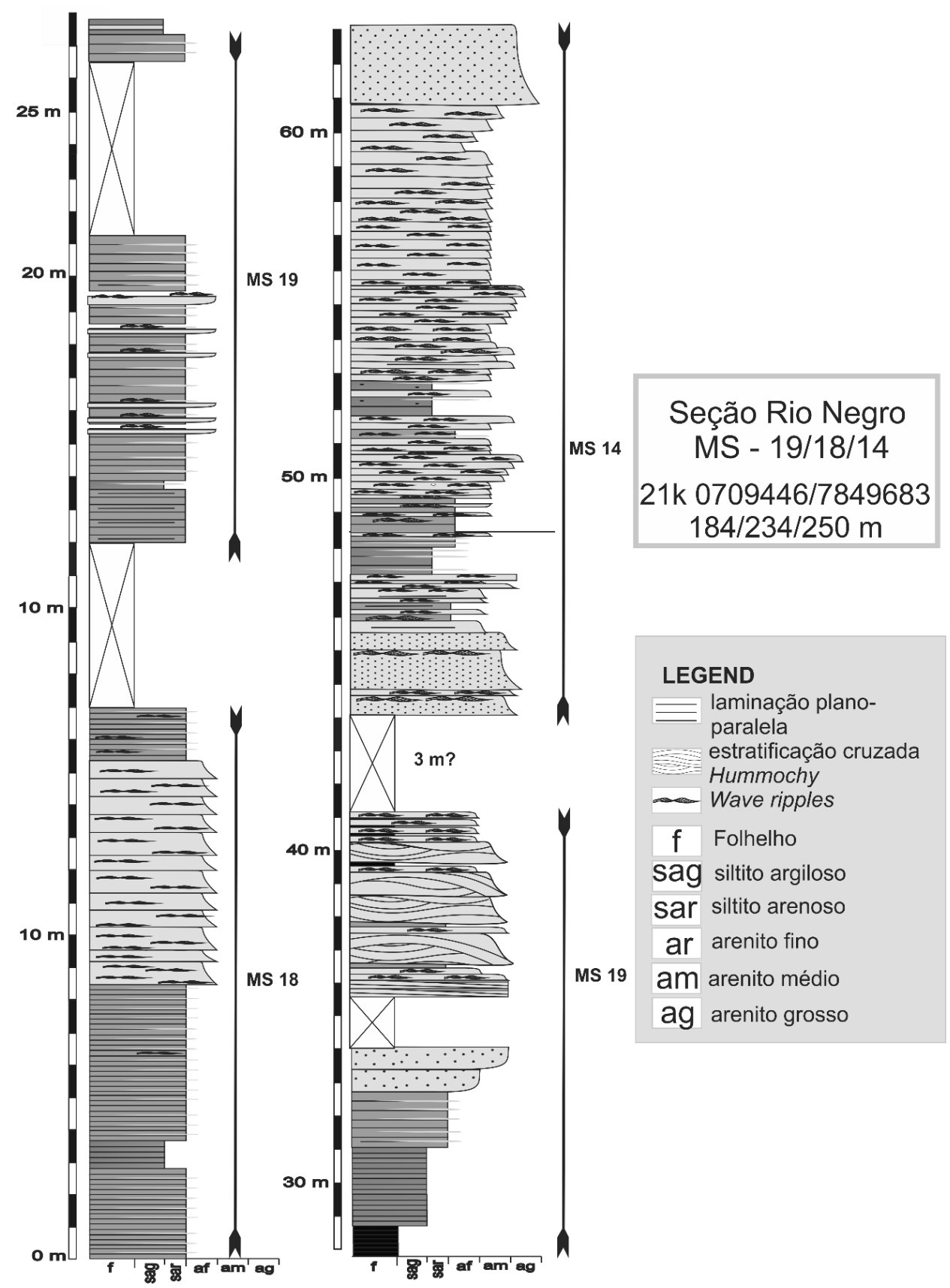

Figura 3 - Seção colunar composta da porção aflorante da Formação Ponta Grossa (Grupo Chapada II inferior) na região do município de Rio Negro. Seção composta pelos afloramentos MS14, MS 18 e MS 19 (ver parte sul da Fig. 11 e Figs. 12 e 13). 

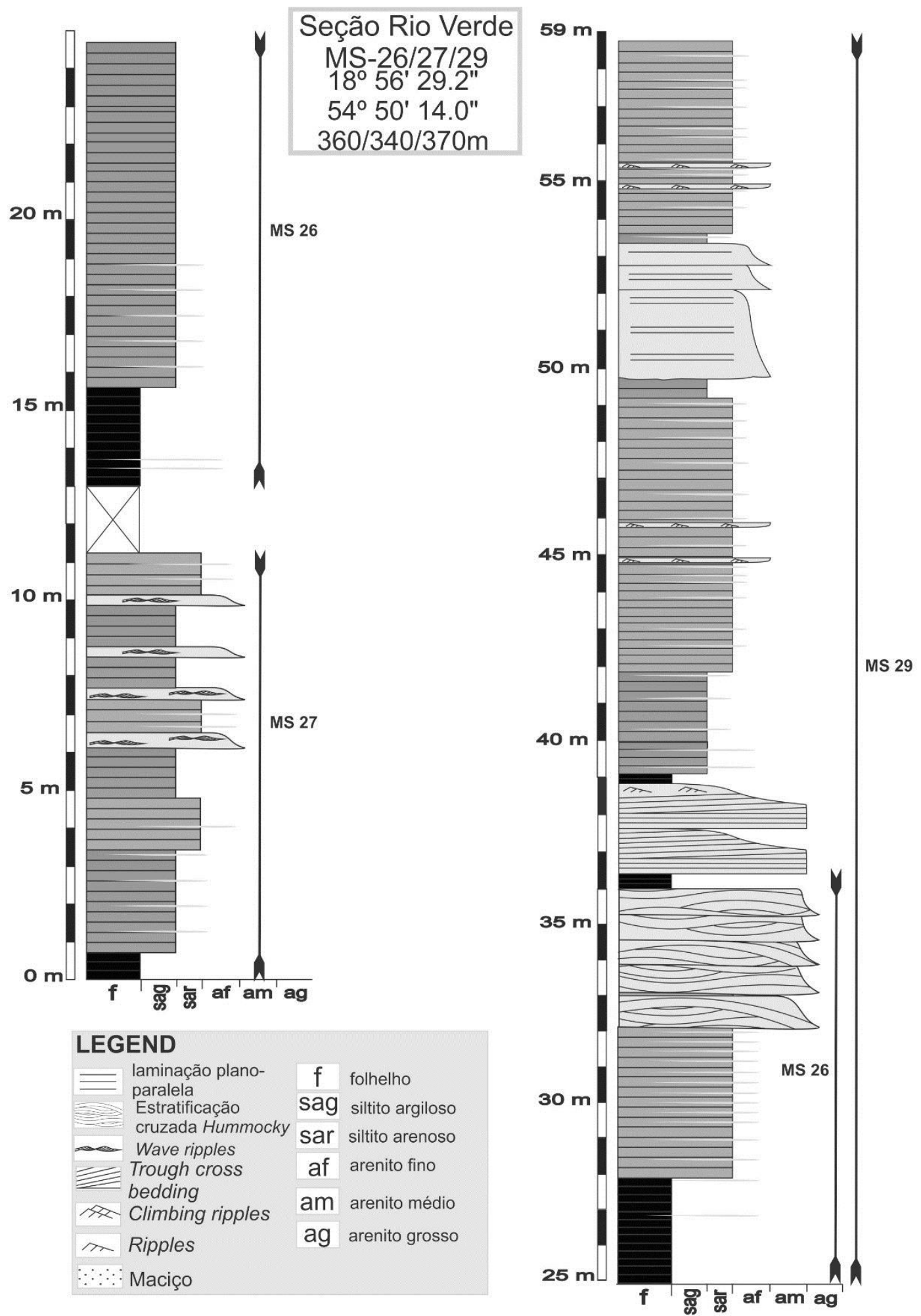

Figura 4 - Seção colunar composta da porção aflorante da Formação Ponta Grossa (Grupo Chapada II inferior) na região do município de Rio Verde de Mato Grosso. Seção composta pelos afloramentos MS 26, MS 27 e MS 29 e correlatas aos afloramentos MS 24 e MS 30 (ver parte norte da fig. 11 e fig. 10). 


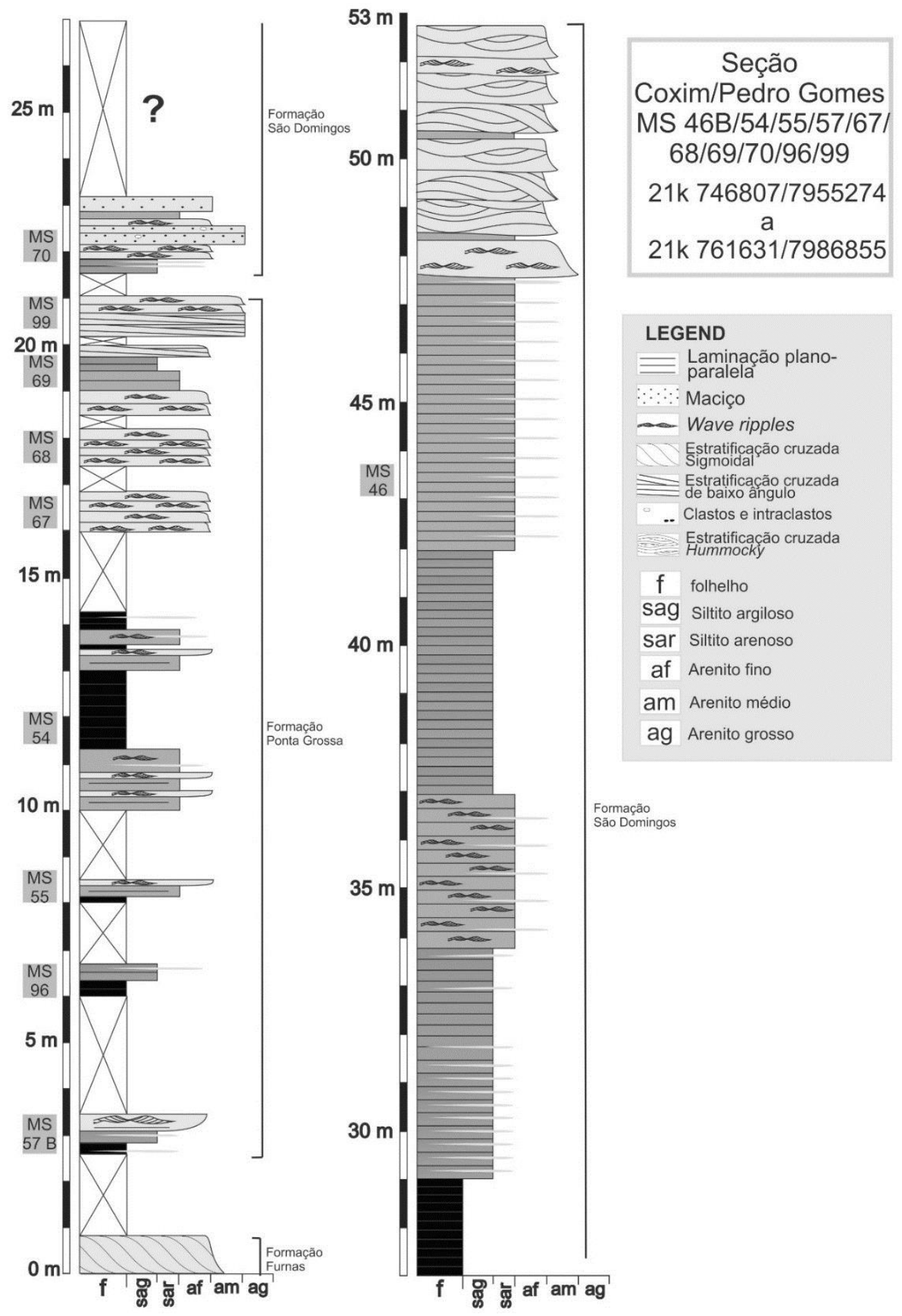

Figura 5 - Seção colunar composta da porção aflorante das formações Ponta Grossa (Grupo Chapada II inferior) e São Domingos (Grupo Chapada IV) na região dos municípios de Coxim e Pedro Gomes. Seção composta pelos afloramentos MS 46B, MS 54, MS 55, MS 57, MS 67, MS 68, MS 69, MS 70, MS 96 e MS 99, com exposição ao longo do Rio Taquari e Fazenda Torrão de Ouro (ver parte sul da fig. 7 e Figs. 8 e 9). Notem a ausência da base da Formação São Domingos (Grupo Chapada II superior e Grupo Chapada III). 
O primeiro fator implica que os intraclastos centimétricos e decimétricos, ou até maiores, de argila e silte, incorporados em grande quantidade nos tilitos do Aquidauana na área de Taboco no mapa I (fig. 14), leva à formação de solos muito similares àqueles que ocorrem em toda a área aflorante da Formação Ponta Grossa no estado (Figs. 16G, H). Souza Jr. et al. (1987) comentaram que uma espessa capa laterítica, associada a oolitos ferruginosos muito bem caracteriza a
Formação Ponta Grossa no Mato Grosso do Sul. A presença de oolitos ferruginosos foi citada como muito comum nesta área por Corrêa et al. $(1976,1979)$ e, devido a escassez de afloramentos em alguns locais, foi usada para estender pela primeira vez a Formação Ponta Grossa até esta região. Este equívoco foi posteriormente seguido nos mapeamentos subsequentes (Araújo et al., 1982, CPRM, 2004; Lacerda Filho et al., 2006).

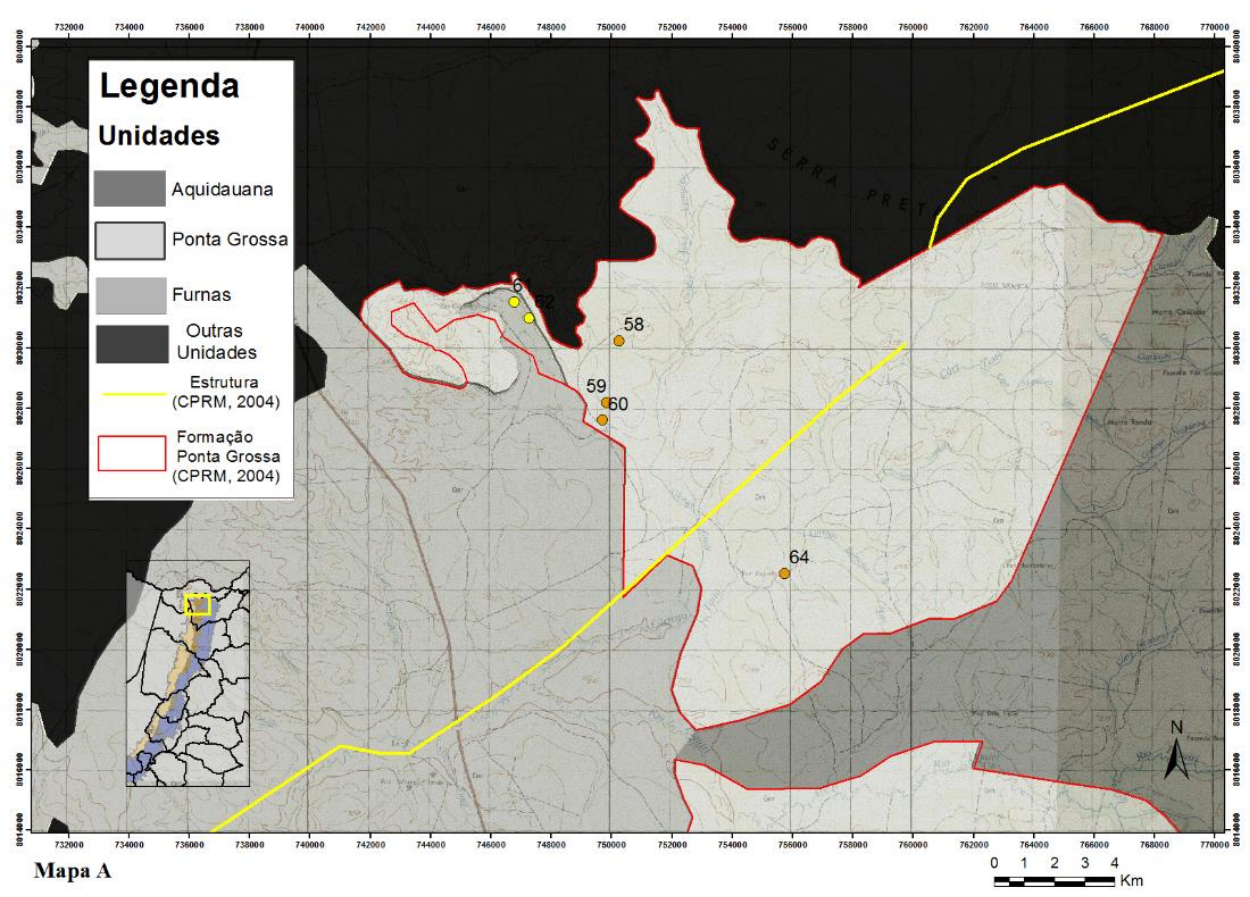

Figura 6 - Mapa da distribuição da Formação Ponta Grossa (Grupo Chapada II inferior?) no extremo norte do estado, em Sonora e Pedro Gomes, conforme o mapa da CPRM (limites em vermelho) e aquela reconhecida nos mapeamentos de campo deste trabalho (cinza mais claro). Números representam os afloramentos visitados; círculos em amarelo - Formação Furnas; círculos em laranja - Formação Ponta Grossa. 


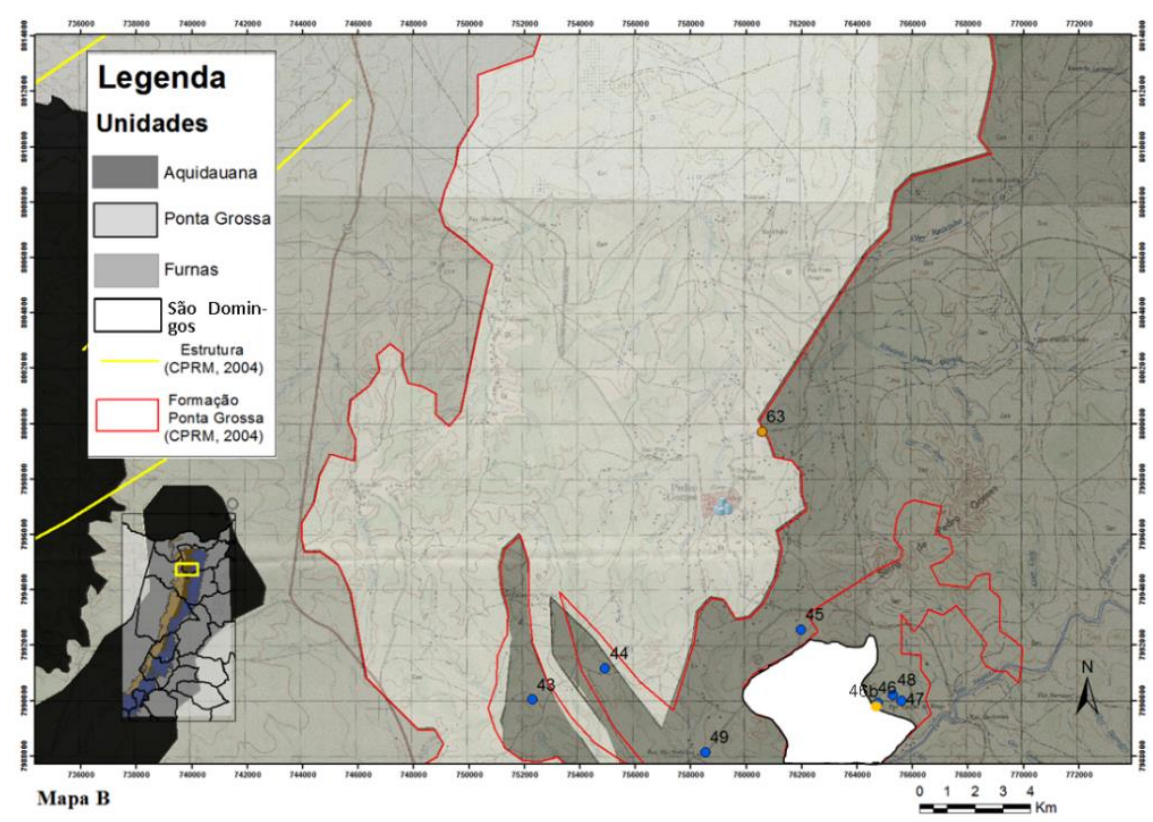

Figura 7 - Mapa da distribuição das formações Ponta Grossa (Grupo Chapada II inferior) e São Domingos (Grupo Chapada IV) no município de Pedro Gomes, conforme o mapa da CPRM (limites em vermelho) e aquela reconhecida nos mapeamentos de campo deste trabalho (cinza mais claro e branco). Números representam os afloramentos visitados; círculos em azul Formação Aquidauana; círculos em laranja - formações Ponta Grossa e São Domingos.

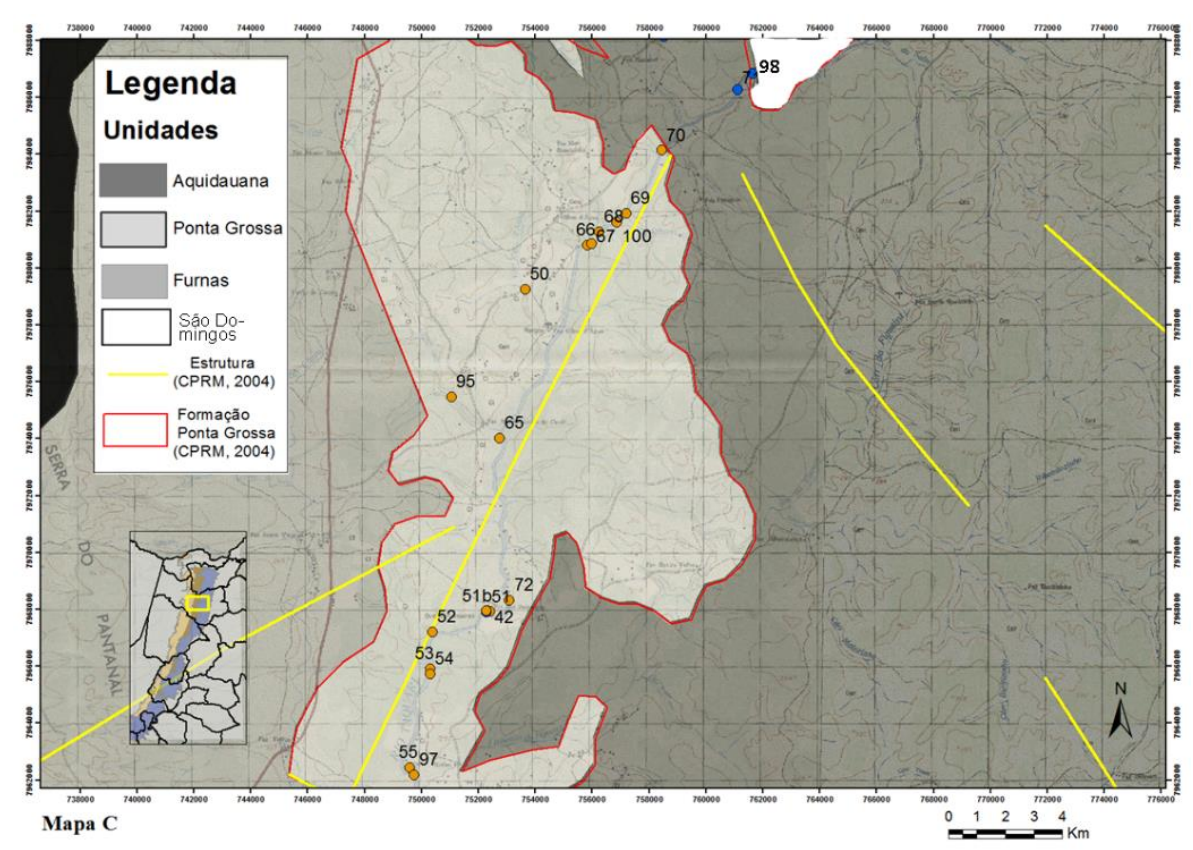

Figura 8 - Mapa da distribuição das formações Ponta Grossa (Grupo Chapada II inferior) e São Domingos (Grupo Chapada IV) no município de Pedro Gomes e Coxim, conforme o mapa da CPRM (limites em vermelho) e aquela reconhecida nos mapeamentos de campo deste trabalho (cinza mais claro e branco). Números representam os afloramentos visitados; círculos em azul - Formação Aquidauana; círculos em laranja - formações Ponta Grossa e São Domingos. 


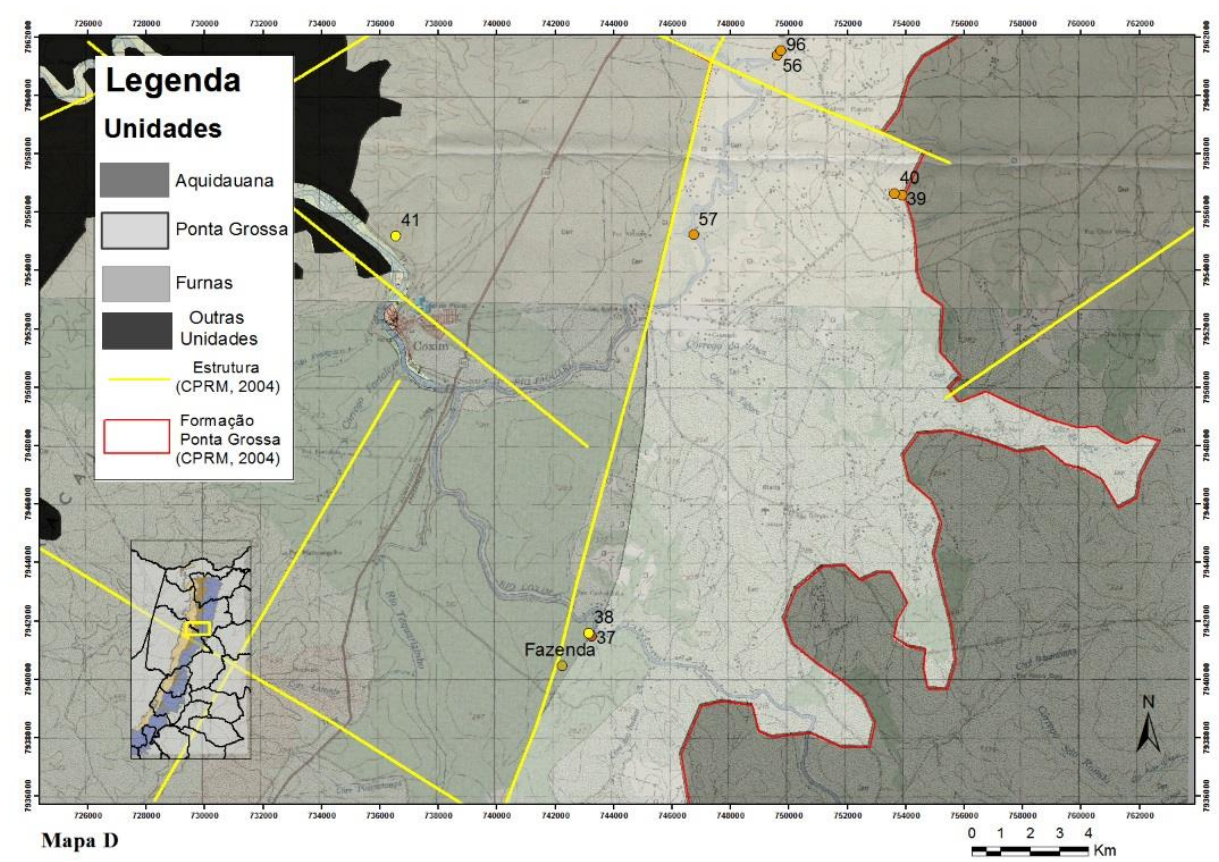

Figura 9 - Mapa da distribuição da Formação Ponta Grossa (Grupo Chapada II inferior) nos municípios de Coxim e Rio Verde de Mato Grosso, conforme o mapa da CPRM (limites em vermelho) e aquela reconhecida nos mapeamentos de campo deste trabalho (cinza mais claro). Números representam os afloramentos visitados; círculos em amarelo - Formação Furnas; círculos em laranja - Formação Ponta Grossa.

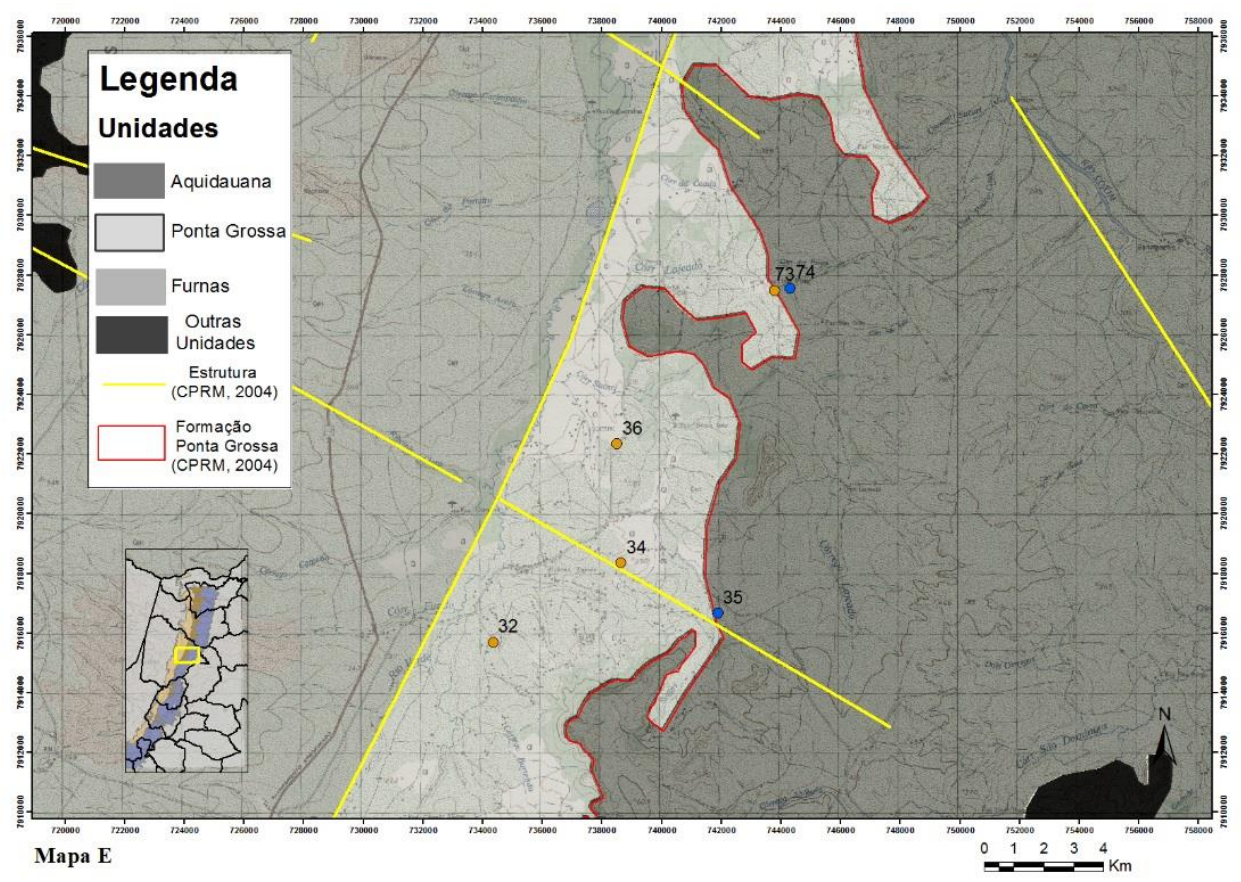

Figura 10 - Mapa da distribuição da Formação Ponta Grossa (Grupo Chapada II inferior) no município de Rio Verde de Mato Grosso, conforme o mapa da CPRM (limites em vermelho) e aquela reconhecida nos mapeamentos de campo deste trabalho (cinza mais claro). Números representam os afloramentos visitados; círculos em laranja - Formação Ponta Grossa; círculos em azul - Formação Aquidauana. 


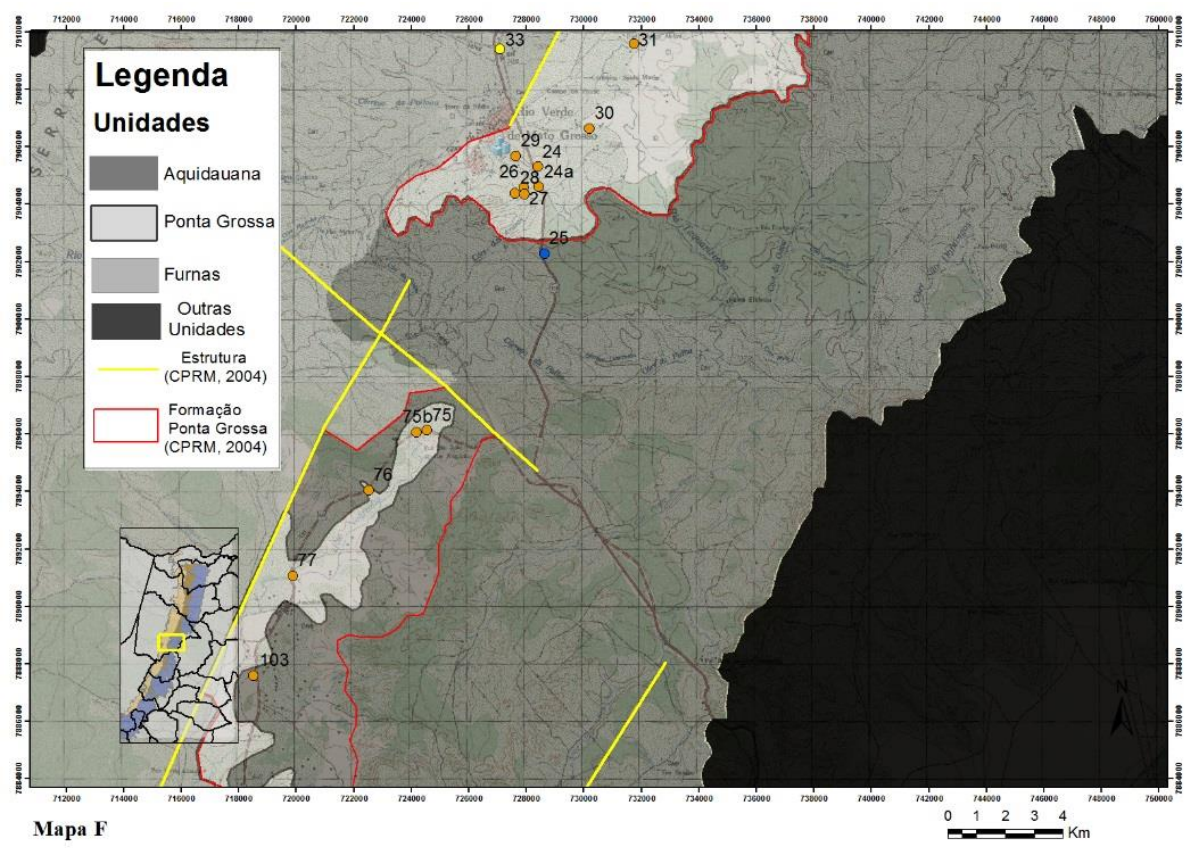

Figura 11 - Mapa da distribuição da Formação Ponta Grossa (Grupo Chapada II inferior) no município de Rio Verde de Mato Grosso, conforme o mapa da CPRM (limites em vermelho) e aquela reconhecida nos mapeamentos de campo deste trabalho (cinza mais claro). Números representam os afloramentos visitados; círculos em amarelo - Formação Furnas; círculos em laranja - Formação Ponta Grossa; círculos em azul - Formação Aquidauana.

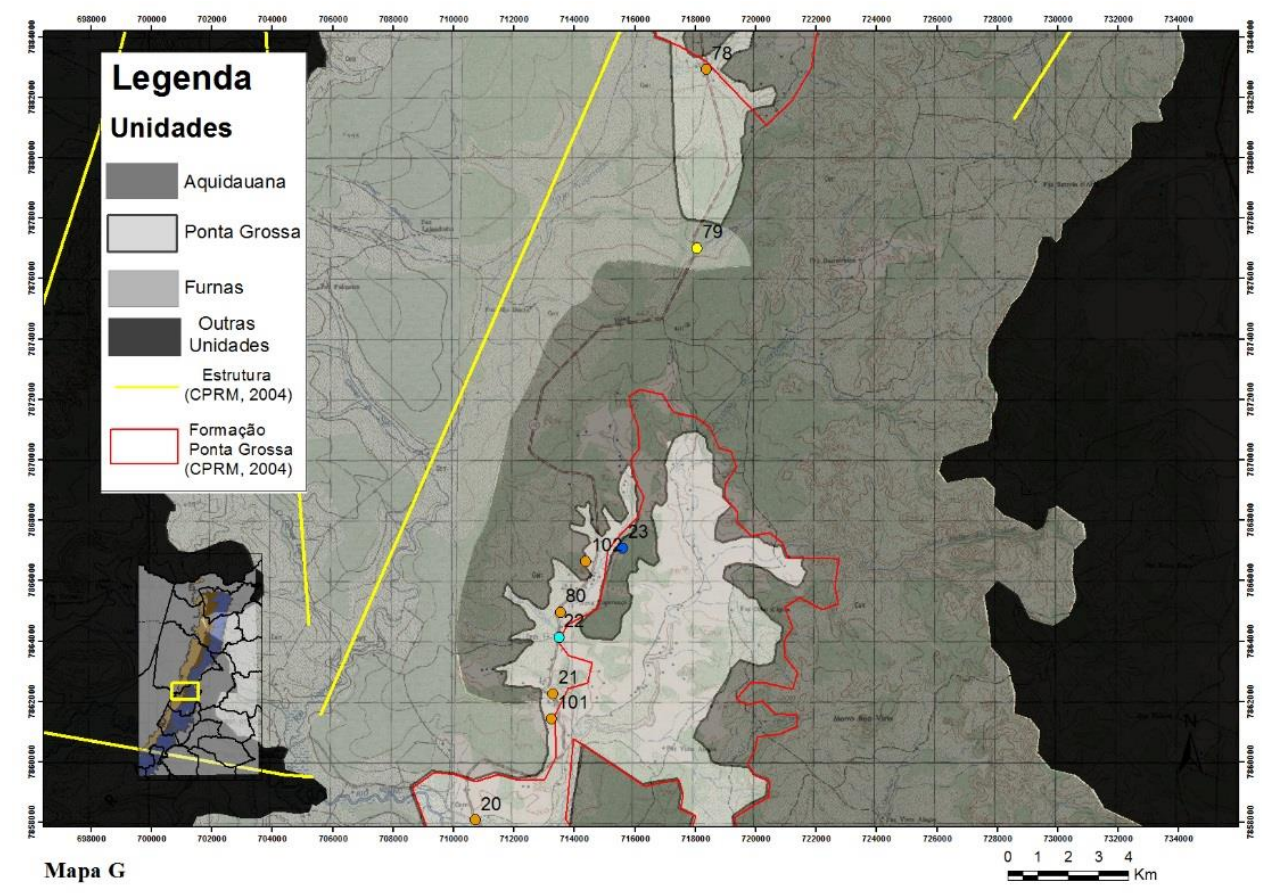

Figura 12 - Mapa da distribuição da Formação Ponta Grossa (Grupo Chapada II inferior) nos municípios de Rio Verde de Mato Grosso e Rio Negro, conforme o mapa da CPRM (limites em vermelho) e aquela reconhecida nos mapeamentos de campo deste trabalho (cinza mais claro). Números representam os afloramentos visitados; círculos em amarelo - Formação Furnas; círculos em laranja - Formação Ponta Grossa; círculos em azul - Formação Aquidauana. 


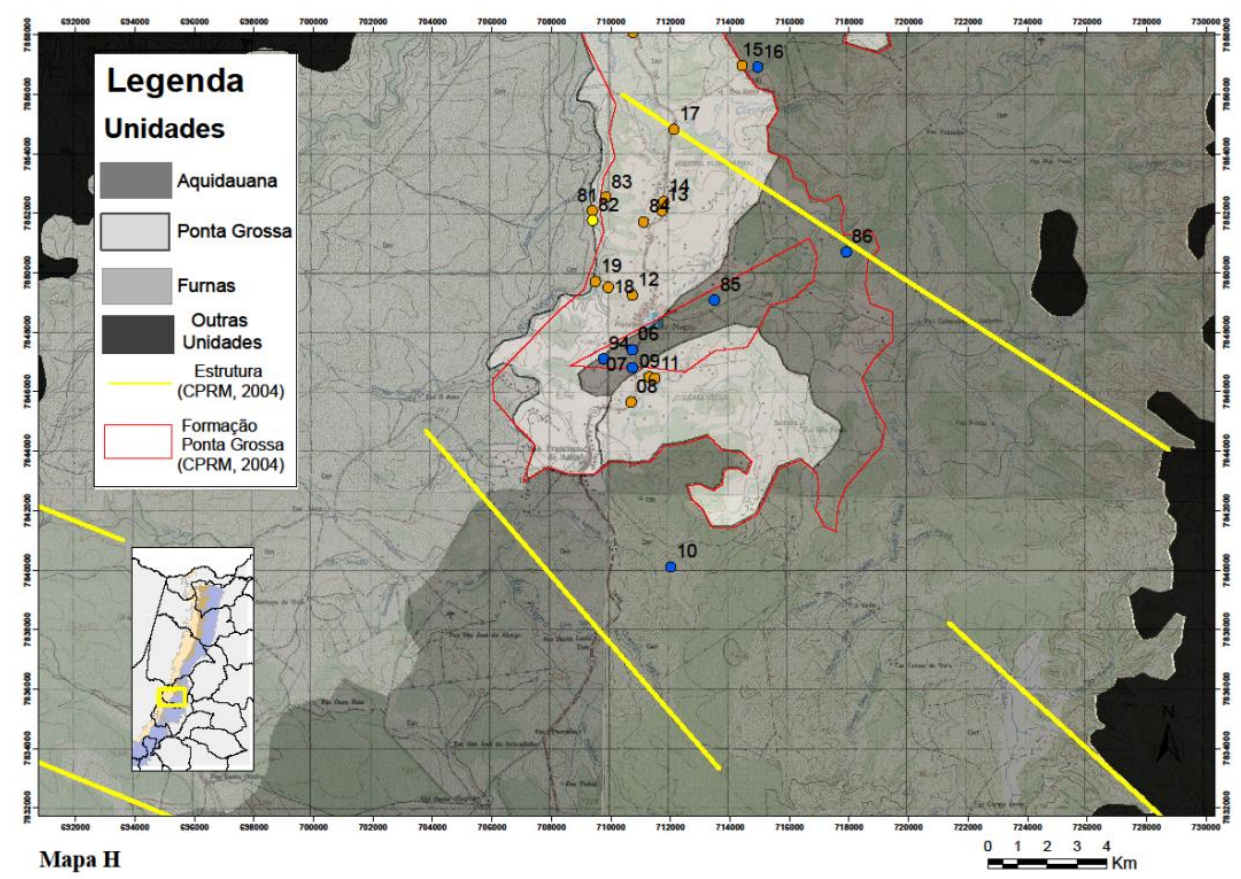

Figura 13 - Mapa da distribuição da Formação Ponta Grossa (Grupo Chapada II inferior) no município de Rio Negro, conforme o mapa da CPRM (limites em vermelho) e aquela reconhecida nos mapeamentos de campo deste trabalho (cinza mais claro). Números representam os afloramentos visitados; círculos em amarelo - Formação Furnas; círculos em laranja - Formação Ponta Grossa; círculos em azul - Formação Aquidauana.

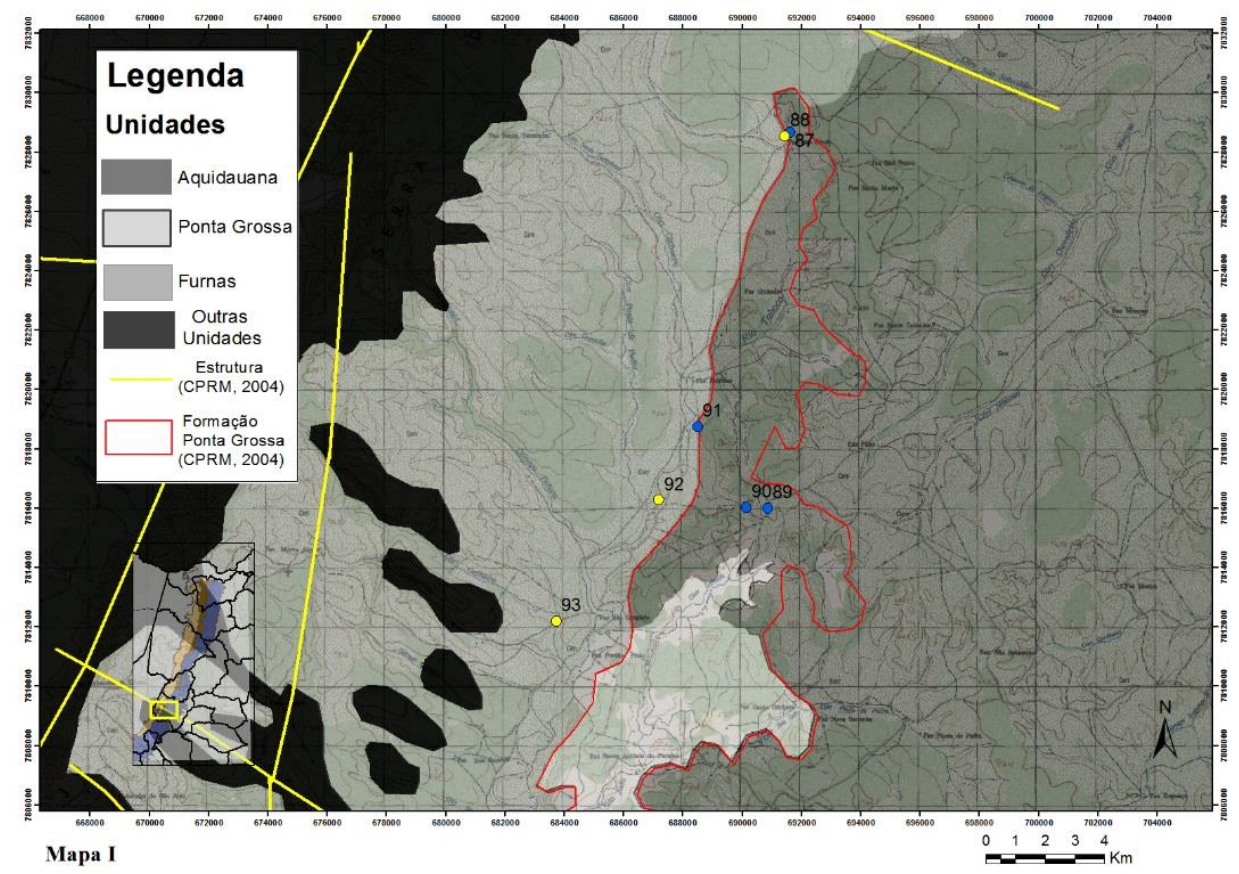

Figura 14 - Mapa da distribuição da Formação Ponta Grossa (Grupo Chapada II inferior) no município de Corguinho, conforme o mapa da CPRM (limites em vermelho) e aquela reconhecida nos mapeamentos de campo deste trabalho (cinza mais claro). Números representam os afloramentos visitados; círculos em amarelo - Formação Furnas; círculos em laranja - Formação Ponta Grossa; círculos em azul - Formação Aquidauana. 


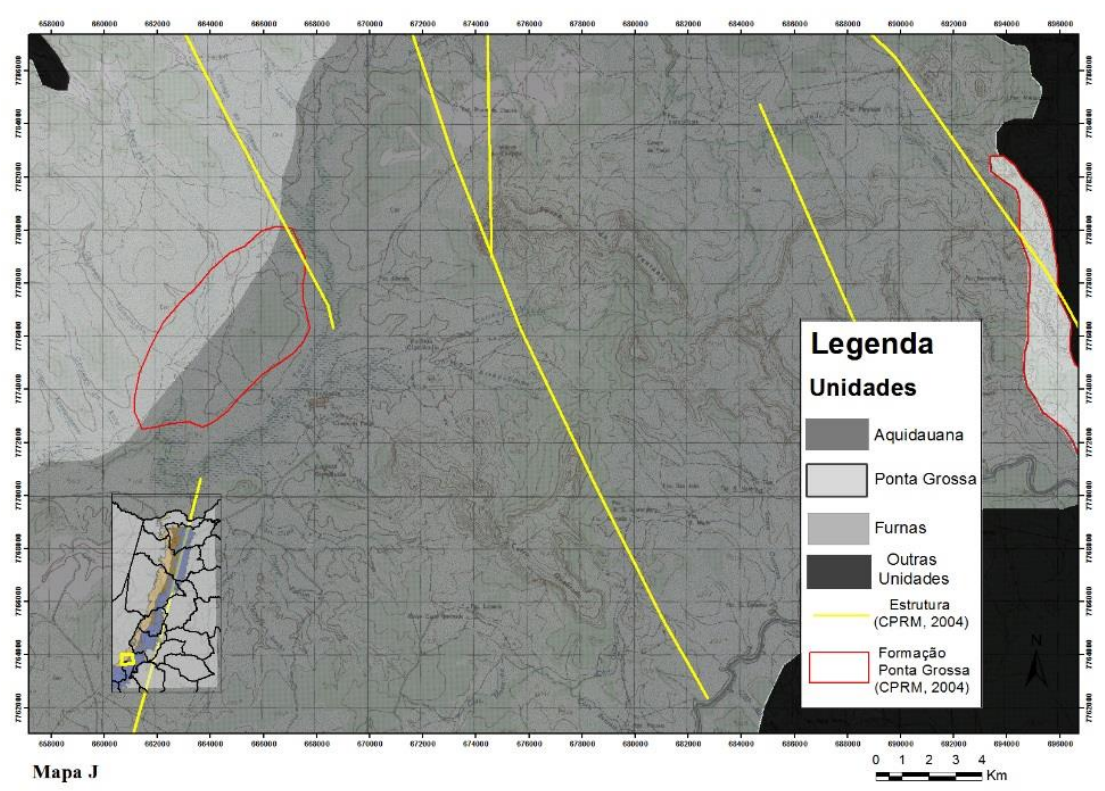

Figura 15 - Mapa da distribuição da suposta Formação Ponta Grossa (Grupo Chapada II inferior) no município de Aquidauana, conforme o mapa da CPRM (limites em vermelho). Mancha da esquerda foi verificada como pertencente às formações Aquidauana e Furnas neste trabalho; mancha da direita não pode ser verificada nos mapeamentos deste trabalho.

Ainda dentro desta mancha, em outras áreas, é nítida a ocorrência da Formação Aquidauana na forma de pequenas escarpas, como ocorre ao sul dos pontos MS89 e MS90, mas, mesmo assim, foram mapeadas como Formação Ponta Grossa. A Formação Ponta Grossa ocorre apenas nas áreas mais ao sul desta mancha nos vales do córrego São João e seu afluente do lado direito, que corre em direção norte-sul.

Nos mapas elaborados pela Companhia de Pesquisa de Recursos Minerais (CPRM 2004, Lacerda Filho, 2006), outra pequena mancha é mapeada imediatamente à oeste da cidade de Cipolândia, como a ocorrência mais meridional da Formação Ponta Grossa no estado. Esta mancha também não foi confirmada pelo presente projeto (mapa J, fig. 15). A área é muito plana e não apresenta afloramentos, no entanto, o solo é formado por uma areia grossa amareloavermelhada, típica de ocorrências da Formação Aquidauana no estado, já sendo representado como pertencendo a esta unidade no mapa do Projeto Radam Brasil
(Araújo et al., 1982). O equívoco deve ter sido gerado por interpretações de imagens de satélites e já havia sido citado por Souza Jr. et al. (1987), que comentaram que a Formação Ponta Grossa se prolonga em direção aproximada $10^{\circ} \mathrm{N}-20^{\circ} \mathrm{E}$ a partir da cidade de Aquidauana. A mancha mais para oeste neste mapa $\mathbf{J}$ não pôde ser verificada em campo, mas provavelmente também seja pertencente à Formação Aquidauana, como representada por Araújo et al. (1982), pois está no limite com a escarpa do Botucatu, conhecida como Serra de Maracaju.

O segundo e terceiro itens são os principais fatores que levaram a confusões em diversas áreas no estado. O topo da Formação Ponta Grossa no estado é de forma geral mais arenosa que na borda leste, composto por areias grossas, que se alternam algumas vezes com arenitos finos e finas lâminas de argila, e culmina em um arenito grosso maciço rosa ou amarelado e alaranjado. Estes muitas vezes podem se confundir com as areias da Formação Aquidauana e, também, com a Formação 
Furnas, pela granulação e cor (Figs. 16A, C, $\mathrm{D}, \mathrm{E})$.

Apesar de Correa et al. $(1976,1979)$ acharem de fácil diferenciação a Formação Ponta Grossa da Formação Aquidauana, colocaram grandes trechos da Formação Aquidauana dentro da Formação Ponta Grossa e vice-versa, como também em outros mapeamentos posteriores.

Esta dificuldade em diferenciar as unidades no estado também já foi citada por Souza Jr. et al. (1987), que comentaram que muitas vezes se torna difícil a distinção local entre as rochas da Formação Ponta Grossa e da base da Formação Aquidauana, uma vez que alguns tipos litológicos de ambas unidades se assemelham muito. Mesmas dúvidas também foram apresentadas com relação a alguns afloramentos em que não puderam ser definidos se pertencem à Formação Ponta Grossa ou à Formação Furnas (e.g. Estação Geológica 4 do seu estudo).

Dificuldades em diferenciar os arenitos da Formação Ponta Grossa dos arenitos da base da Formação Aquidauana já foram citadas por Andrade e Camarço (1980), para a região leste das cidades de Iporá e Amorinópolis, principalmente quando falta o membro superior (caso da maior parte do contato entre as formações Ponta Grossa e Aquidauana no Mato Grosso do Sul), sendo o único critério seguro a presença de diamictitos na Formação Aquidauana, que nem sempre são encontrados. Esta dificuldade é novamente lembrada por Andrade (1988). Apesar dos autores estarem tratando mais especificamente de sua unidade III do Grupo Chapada, o mesmo pode ser dito para o topo da Formação Ponta Grossa (Unidade II inferior) no Mato Grosso do Sul.

A base da Formação Aquidauana no estado é composta por estratificações cruzadas de grande porte, apresentando clastos, muito similares à Formação Furnas, no entanto o contato é evidenciado no ponto MS21 e no poço artesiano perfurado no ponto MS94, logo a oeste do ponto MS06 (Figs. 12 e 13). O poço começa com uns doze metros de arenito que possivelmente representa a base da Formação Aquidauana e topo da Formação Ponta Grossa. Estas estratificações cruzadas da base da Formação Aquidauana já haviam sido observadas por Souza Jr. et al. (1987) na estação geológica 03 do seu estudo. 


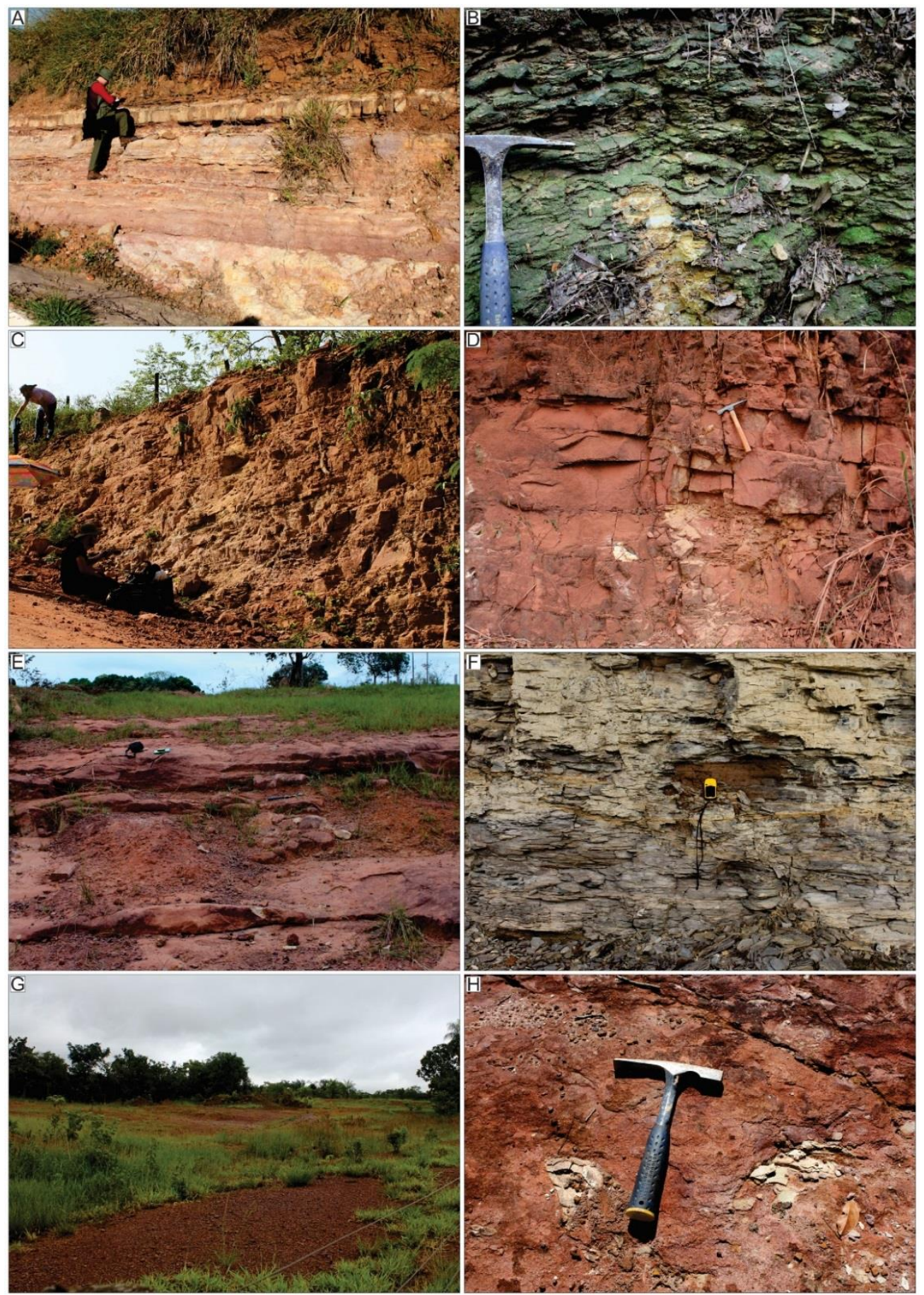

Figura 16 - Afloramentos do estado do Mato Grosso do Sul: A) afloramento Estância Nhecolândia (MS14), mostrando o aspecto do arenito avermelhado da Formação Ponta Grossa (mapa H, Fig. 13); B e C) siltito arenoso da base e tempestitos do topo, respectivamente do afloramento MS19, seção Estrada da Ponte Nova (mapa H, Fig. 13); D) arenitos com estratificação cruzada da base da Formação Aquidauana, MS21 (mapa G, fig. 12); E) arenitos maciços finos a médios rosados e arroxeados do topo da Formação Ponta Grossa, MS22 (mapa G, Fig. 12); F) folhelhos do afloramento MS72, margem esquerda do Rio Taquari (mapa C, Fig. 8); G) afloramento MS87, mostrando o aspecto do solo em área da Formação Aquidauana parecido com solos de áreas da Formação Ponta Grossa, coberto por oólitos ferruginosos (mapa I, Fig. 14); H) afloramento MS91, mostrando os arenitos da Formação Aquidauana com intraclastos de siltito e arenito da Formação Ponta Grossa (mapa I, Fig. 14). 

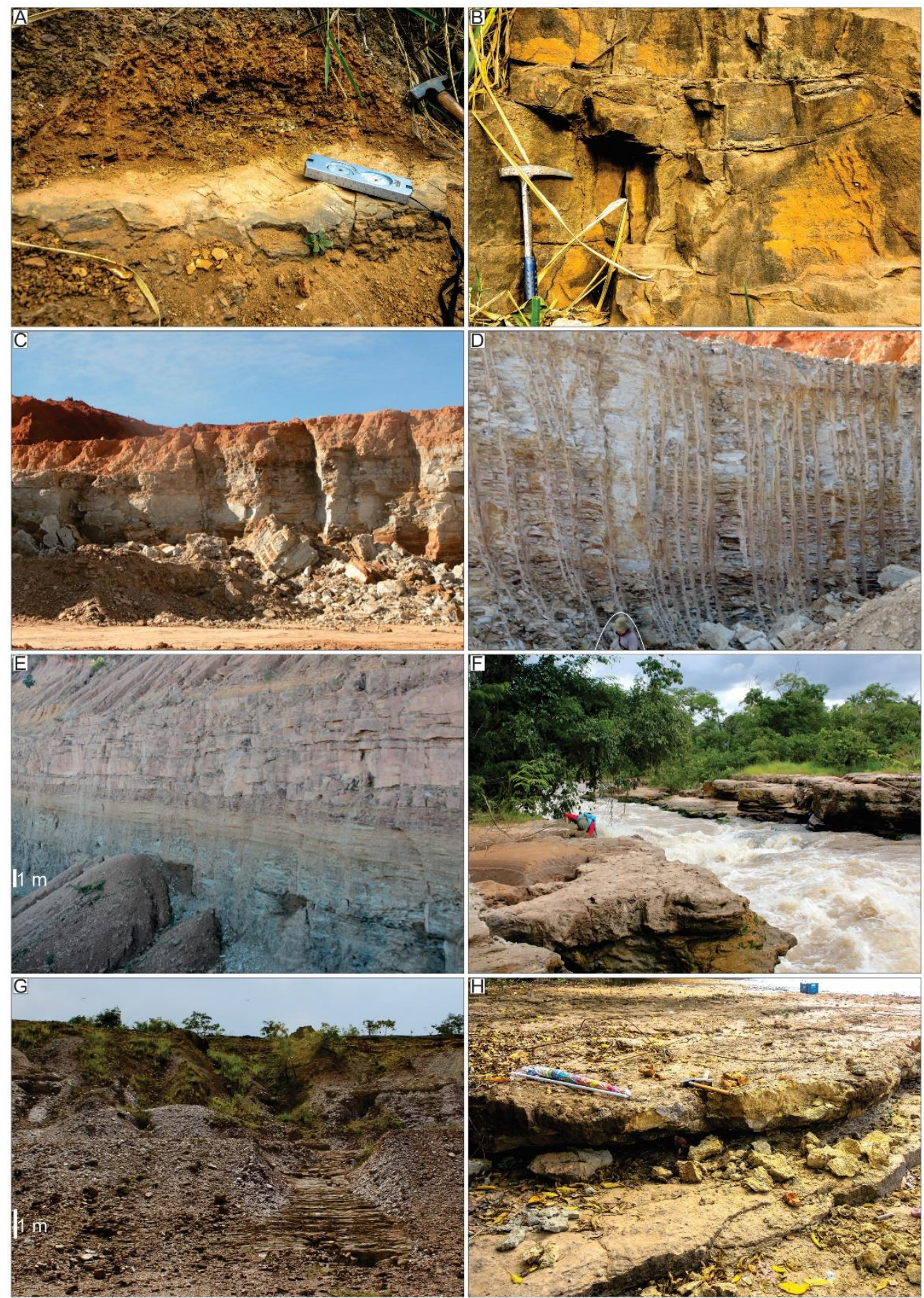

Figura 17 - Afloramentos do estado do Mato Grosso do Sul: A e B) afloramento MS24 (entrada de Rio Verde), apresentando marcas de onda simétricas com orientação SW-NE $\left(60^{\circ}\right)$ e estratificação cruzada Hummocky, respectivamente; C e D) afloramento Cerâmica Campo Grande (MS26), apresentando as frentes de lavra de siltitos e argilitos recobertos por tempestitos intemperizados; E) afloramento Pedreira Fênix (MS29), mostrando folhelhos na base recobertos por tempestitos, correlatos ao afloramento Cerâmica Campo Grande; F) afloramento Cachoeira das Palmeiras (MS51), com arenitos maciços de fácies de praia nas margens do Rio Taquari; G) afloramento Fazenda Torrão de Ouro (MS46B), com siltitos e arenitos finos do Frasniano; H) afloramento Corredeira da Benedita (MS70), com arenitos laminados do Givetiano no Rio Taquari. 
Possivelmente a base arenosa, com estratificação cruzadas do Aquidauana, foi que levou Almeida (1954), que estudando a sequência de 110 metros expostos de sedimentos acima dos rios Porube (em Paraíso) e Dourado, onde atravessa a rodovia de Guiratinga a Poxoréu, no Mato Grosso, apontar que na "parte superior dessa sequência há vários metros de arenito branco, grosseiro, localmente conglomerático, contendo seixos rolados de quartzo com até $15 \mathrm{~cm}$ de diâmetro". Estas camadas superiores, que conforme Almeida perfazem em torno de 80 metros, foram interpretadas como uma fácies Furnas decorrentes de regressão marinha, similar aos arenitos do Membro Tibagi no Paraná. No entanto, esta deve ser a base da Formação Aquidauna local, similar ao que ocorre em Rio Negro.

A cor diferenciada do arenito Furnas em muitos pontos na borda noroeste também tem levado a erros de interpretação geológica, como de Derby (1890), que considerou mesozoicos os arenitos da Formação Furnas, de cor vermelha, na Chapada dos Guimarães; posteriormente reinterpretados corretamente por Almeida (1954).

O mesmo tipo de interpretação também já havia sido feito por Beurlen (1956) que enquadrou toda a Formação Furnas como o arenito inferior pré-glacial da Formação Aquidauana, inclusive entre o norte do Rio Taboco e o Rio Negro.

Problemas com a identificação destes arenitos das três formações têm levado à diversas incongruências em mapas geológicos, sendo que as maiores estão situadas nos nossos mapas F, G e H (Figs. 11, 12 e 13, respectivamente). No mapa $H$ toda a área a leste de Rio Negro mapeada tradicionalmente como Formação Ponta Grossa (Radam Brasil, 1982; CPRM, 2004; Lacerda Filho et al., 2006) é, na verdade, área aflorante da Formação Aquidauana. Assim também o mapa $\mathrm{G}$ mostra que áreas mapeadas como Formação Ponta Grossa são na verdade Formação Aquidauana, sendo que o contato pode ser encontrado no ponto MS21. No mesmo mapa G existe uma faixa mapeada anteriormente como Formação Furnas, que se trata de afloramentos de arenitos grossos da Formação Ponta Grossa (MS22, MS80, MS102).

Ainda no mapa G (Fig. 12) estendemos por alguns quilômetros a área de ocorrência da Formação Ponta Grossa ao sul do ponto MS78 até pouco ao sul do ponto MS79, área também considerada anteriormente como Formação Furnas. Esta ocorrência da Formação Ponta Grossa se estende pelo vale deste e de outros córregos da área, sendo limitada a oeste pelas formações Aquidauana nos altos e Furnas nos vales. Isso ocorre também na mancha sul da Formação Ponta Grossa do Mapa F, que passa a estar restrito a cotas mais baixas nos vales dos rios, sendo o restante considerado Formação Aquidauna. Note que o contato da Formação Furnas com as formações Ponta Grossa e Aquidauana é por falha, o que pode estar ocorrendo também no mapa $G$, mas não pôde ser verificado.

Outro mapa que apresenta pequena, mas importante modificação é o Mapa B (Fig. 7), onde parte da mancha de idade devoniana à leste, situado dentro da Fazenda Torrão de Ouro em Pedro Gomes, é na verdade pertencente à Formação Aquidauana. Nesta mancha foi encontrado o Devoniano mais novo até agora no Mato Grosso do Sul (Frasniano - Afloramento MS46B, Fazenda Torrão de Ouro, Mendlowicz Mauller, 2017, relatório de palinologia não publicado do projeto $\mathrm{CNPq}$, chamada Universal, processo 474952/20134), o que indica que esta mancha de Devoniano, provavelmente, está preservada em um bloco abatido (Fig. 17G).

Aparentemente o morro da Fazenda Torrão de Ouro é o afloramento de idade mais nova de todo o Devoniano da bacia. Idade frasniana apenas foi identificada recentemente em sub-superfície em área relativamente próxima no estado do Mato Grosso (Mendlowicz Mauller, 2007; Souza et al., 2013), no poço do município de Dom Aquino 01-DA-MT. Segundo estes autores 
os folhelhos que representam a assinatura da transição Givetiano-Frasniano, e a superfície de inundação máxima ocorrida no Frasniano, podem ser usados como marcos cronoestratigráficos, sendo, também, objeto de interesse para a exploração de hidrocarbonetos.

Portanto, a indicação de Melo (1985) da ocorrência da unidade 4 (Grupo Chapada IV = Formação São Domingos, neste trabalho) no corte da Serra da Boa Sentença, a sudeste de Rio Verde de Mato Grosso, está incorreta, sendo que apenas a unidade 2 inferior (Formação Ponta Grossa) parece estar presente nesta área com base nas datações realizadas neste projeto (Mendlowicz Mauller, 2017, relatório de palinologia não publicado do projeto $\mathrm{CNPq}$, chamada Universal, processo 474952/20134).

Conforme Melo (1985) o contato entre o Grupo Chapada I, que hoje sabemos ser correlata a Formação Furnas, e o Grupo Chapada II inferior, correlata a Formação Ponta Grossa (sensu Grahn et al., 2013), na maioria da borda noroeste, mesmo em subsuperfície ocorre por contato concordante e gradacional. O contato discordante e erosivo conforme Melo (1985) seria a exceção e estaria restrito as margens da bacia, como já apontado por Andrade e Camarço (1980), se tornando gradacional para o centro da bacia. No Mato Grosso do Sul aparentemente a faixa expositiva mais larga da Formação Ponta Grossa (Grupo Chapada II inferior), em Pedro Gomes no norte do estado, apresenta um contato gradacional com a Formação Furnas (Grupo Chapada I). A partir de aproximadamente $13 \mathrm{~km}$ a NNE da cidade de Coxim este contato parece ocorrer por falha normal em praticamente toda a área expositiva para o sul até a localidade de Juscelândia, ao sul de Rio Verde de Mato Grosso (figs. 7, 8, 9, 10 e 11), como representado em vários mapas geológicos (Del'Arco et al., 1982; CPRM, 2004; Lacerda Filho et al., 2006). No presente trabalho se amplia a área onde ocorrem estes contatos por falha e é possível notar que, em áreas mais para o sul, o contato da Formação Furnas parece ocorrer por falha não somente com a Formação Ponta Grossa, mas também, algumas vezes, diretamente com a Formação Aquidauana, ao longo do Rio Negro e Rio Taboco, que correm encaixados em grande parte de seus cursos (Figs. 11, 12, 13 e 14). Controle estrutural para parte do Rio Negro, assim como para o Rio Taboco já foram sugeridos por diversos autores (Franco e Pinheiro, 1982; Sausen e Kux, 1982; Del'Arco et al., 1982; CPRM, 20014; Lacerda Filho et al., 2006). Nos afloramentos MS 19 e MS 81, foi possível verificar a presença de rochas da Formação Furnas na margem direita do rio Negro e da Formação Ponta Grossa na margem esquerda, mostrando que as duas unidades estão em contato lateral.

A base da Formação São Domingos (Chapada II superior e o Grupo Chapada III) parece estar ausente na área estudada. Pelo menos não foi encontrada, em nenhuma das dezenas de datações palinológicas, afloramentos de idade emsiana inicial ou eifeliana. O topo da Formação São Domingos (Grupo Chapada IV) foi encontrado apenas em dois afloramentos (MS46b e MS70, Frasniano e Givetiano respectivamente) na área leste de ocorrência em Pedro Gomes (Figs. 17G, H). No perfil ao longo do Rio Taquari ocorre uma seção de mais de 40 quilômetros de comprimento, onde deve aflorar em torno de 30 metros de rochas do Devoniano, uma vez que as camadas mergulham em torno de $3^{\circ}$ no sentido da jusante do rio (figs. 5, 17F, H). A maioria do perfil é representado por camadas da Formação Ponta Grossa (Pragiano-Emsiano inicial), sendo que nos últimos 10 metros, apenas o topo, é datado como Givetiano, havendo, muito possivelmente, um hiato de não deposição entre o Emsiano inicial e o Givetiano, não havendo evidências de disconformidades. Isto, associado ao aumento da granulometria em direção ao topo deste perfil e também nas ocorrências mais ao sul, em Rio Negro e Rio Verde, parecem indicar que ocorreu uma ativação tectônica ao 
longo do Emsiano e o soerguimento do arco de Campo Grande tenha se dado justamente durante o Emsiano médio/tardio, expulsando o mar Devoniano da área. Ao que parece, somente com o evento transgressivo na passagem do EifelianoGivetiano foi que novamente retornou à deposição marinha em áreas mais ao norte do estado, com a Formação São Domingos (Grupo Chapada IV) ainda arenosa no Givetiano, diferente dos pelitos que ocorrem na borda leste e em Goiás. Reforça esta hipótese a presença de fauna malvinocáfrica clímax (sensu Bosetti et al., 2012) nos afloramentos de idade pragiana a emsiana inicial, muito similar à fauna de mesma idade no Paraná, evidenciando a ausência de uma barreira geográfica efetiva entre as duas sub-bacias, conforme já aventado por Sedorko et al. (2018d).

A espessura da Formação Ponta Grossa no estado também precisa ser discutida. Na literatura são encontradas informações muito variadas, porém a maioria aponta a unidade como pouco espessa. Correa et al. (1976, 1979) comentaram que a espessura média estimada para esta unidade no estado foi de 70 metros, a qual tenderia a aumentar, todavia, para norte-nordeste, além da área do projeto.

Conforme Pimenta e Souza (1978 apud Del'Arco et al.,1982) a Formação Ponta Grossa teria uma espessura de 150 metros a oeste de Pedro Gomes, sendo que a leste de Coxim Del'Arco et al. (1982) estimaram uma espessura de apenas 60 metros. Souza Jr. et al. (1987) comentaram que possivelmente a espessura pode chegar a 200 metros, apesar de não ultrapassar esta marca.

Conforme Del'Arco et al. (1982) a diminuição da espessura da Formação Ponta Grossa de norte para sul, na área da Folha SE.21 - Corumbá, possivelmente está relacionada por efeitos de Arco de Campo Grande, cujos registros são notados a sul da Folha SE.21-Z-D. No presente trabalho também notou-se esta diminuição da espessura, porém não tão pronunciada.
Dados de empresas perfuradoras de poços, conseguidas por informações verbais, mostram espessura de aproximadamente 200 metros na região de Rio Negro, o que evidencia que possivelmente o Arco de Campo Grande não estivesse tão desenvolvido no Devoniano Inferior. Talvez o gradual aumento na granulometria do sedimento para o topo da Formação Ponta Grossa, culminando com os arenitos grossos de Rio Negro (MS13 e MS14) e com espessos tempestitos em Rio Negro e Rio Verde (MS 18, MS 24, MS 26, MS29 e MS 30), esteja relacionado à ativação tectônica deste arco durante o Emsiano, provocando uma regressão na área, o que estaria de acordo com Aguiar (2004) e Pereira et al. (2007) para quem o pacote arenoso do topo da seção em Rio Verde estaria relacionado a uma progradação de depósitos de antepraia bacia adentro, em resposta a um processo de regressão forçada (Figs. 16C e 17B, C, D, E). Estas seções em Rio Negro e Rio Verde (Figs. 3 e 4) seriam equivalentes à metade superior da sequência Siluro-devoniana de Sedorko et al. (2018a), onde os sedimentitos grossos do topo representariam o Trato de Sistemas de Mar Alto, em uma regressão induzida tectonicamente.

A ausência de sedimentos da Formação São Domingos (Devoniano Inferior tardio e Devoniano Médio e Superior) ao sul da área de ocorrência e seu aparecimento restrito em áreas ao norte do estado (MS70 e MS46b) e mais amplamente distribuído no estado do Mato Grosso, na Chapada dos Guimarães (e.g. Melo, 1988) e também em Rondonópolis (Mendlowicz Mauller, 2007; Mendlowicz Mauller et al., 2009), além de sua ocorrência como arenitos em áreas mais ao centro da bacia em Mato Grosso do Sul (poço Well 2-RP-1MS, Grahn et al., 2002), parecem reforçar esta hipótese.

No ponto MS94, dentro da Fazenda de Lair Sanchez situada na entrada da cidade de Rio Negro, vindo de Corguinho, a empresa Eletrobombas, de Campo Grande, estava perfurando um poço na 
oportunidade de nosso campo. Conforme o responsável Sr. Leandro Ferreira de Andrade, já haviam furado 200 metros, sendo os 12 primeiros em arenito, e esperava furar mais 10 a 20 metros para alcançar o aquífero da Formação Furnas. Também comentou que na Chácara Ourolândia, 4 a 5 quilômetros a sudeste a empresa furou outro poço com 100 metros de Formação Ponta Grossa. Da mesma forma, o dono de uma empresa de perfuração de poços artesianos em Coxim indicou que na localidade de São Romão, aproximadamente $10 \mathrm{~km}$ ao sul de Silvolândia perfurou 300 metros para passar a Formação Ponta Grossa. Também afirma que perfurou 240 metros e não conseguiu atravessar a Formação Ponta Grossa na Fazenda Torrão de Ouro, em Pedro Gomes. Da mesma forma não conseguiu atravessar esta unidade em perfuração de 400 metros, a aproximadamente oito quilômetros a nordeste de Pedro Gomes, pegando a estrada MS 215.

Obviamente que estes relatos precisam ser confirmados, porém vindo de duas fontes distintas evidenciam que a Formação Ponta Grossa é bem mais espessa na área do que se imaginava antes e muito provavelmente sua espessura é bastante variável devido ao intenso fraturamento e abatimento de blocos, já mencionado por outros autores (e.g. Amaral Filho, 1989), que parece ocorrer nesta área geomorfológica denominada de Depressão Interpatamares ou Depressão Embutida na Serra de Maracaju (Franco e Pinheiro, 1982). Depressão possivelmente associada com o reativamento de um lineamento transbrasiliano, associado com a abertura do Atlântico Sul. Esta espessura variável devido a blocos de falha também já havia sido descrita para outras regiões da borda noroeste em Mato Grosso e Goiás (e.g. Andrade e Camarço, 1980). Oliveira e Muhlmann (1967) comentaram que a Formação Ponta Grossa, na Chapada dos Guimarães, apresenta-se, sob o ponto de vista estrutural, seccionada por falhas, muitas com grande comprimento e deslocamento.

As informações acima descritas indicam que exista um possível tectonismo singenético concomitante com a deposição da Formação Ponta Grossa (Grupo Chapada II inferior), principalmente para o topo da unidade (sensu Grahn et al., 2013). Esta apresenta sedimentitos mais grossos para o topo, com grandes tempestitos, que podem ser evidências de uma progradação influenciada pela tectônica, que culmina com o hiato deposicional do Emsiano médio ao Givetiano inicial na área. $O$ soerguimento do Arco de Campo Grande durante este momento talvez seja responsável pela magnitude da regressão na região e pode estar associado a uma reativação tectônica ao final do ciclo Cordilherano, relacionada ao choque do microcontinente Chilenia (Alvarez et al., 2011). Conforme Rapela (2000) a primeira contração da sequência sedimentar Precordilheira ocorre no Siluriano tardioDevoniano inicial, que é consistente com dados de K/Ar sugerindo uma impressão termal (thermal overprint) durante 425-400 Ma. No entanto Willner et al. (2011) determinou que o pico do metamorfismo ocorreu no Devoniano Médio (390 Ma).

A Formação do Arco de Campo Grande pode ter levado a retirada do mar epicontinental da área do Mato Grosso do Sul, que somente retornou com a subida do nível do mar global durante o Devoniano Médio, como evidenciado pela presença de afloramentos de idade givetiana e frasniana na área mais ao norte. $\mathrm{O}$ afloramento de idade givetiana provavelmente está posicionado na parte superior da sequência Devoniana II de Sedorko et al. (2018a), considerando que os ciclos tenham sido semelhantes em toda a bacia.

Não podemos excluir a possibilidade da não ocorrência de camadas mais novas que Emsiano inicial na área mais ao sul estar associada à maior intensidade das glaciações carboníferas em direção ao sul, como já atestado por diversos autores (Beurlen, 1956; Almeida, 1954; Rocha- 
Campos e Farjallat, 1966), que acabaria por erodir o registro da Formação São Domingos. No entanto, muitas evidências reforçam idéia contrária: 1) ausência do Emsiano médio-Eifeliano na área aflorante no estado, incluindo na parte norte; 2) ausência de evidência de desconformidade no registro sedimentar; 3) Givetiano aparentemente posicionado diretamente em cima do Emsiano inicial; 4) ausência do Eifeliano que somente irá ocorrer para o centro da bacia como arenitos no poço Well 2-RP-1-MS; 5) sedimentos mais grossos nos topos dos perfis regionais no Emsiano inicial, em especial mais ao sul em Rio Negro e Rio Verde; 6) marcas de onda presentes apenas no topo dos perfis regionais em áreas mais ao sul no estado, no Emsiano inicial, demonstrando uma linha de costa no sentido NW-SE (fig. 17A) ou até mesmo W-E e talvez um arco de Campo Grande mais desenvolvido apenas a partir do Emsiano médio/tardio.

Assine et al. (1998), ao tratar do Grupo Rio Ivaí, de idade ordovíciosiluriana, não considera em seu mapa de isópacas a bacia compartimentada em duas sub-bacias. Arco de Assunção ainda não teria expressão geomorfológica, tendo a Bacia do Paraná continuidade física com as bacias Chaco-Paranense e do Chaco-Boreal (Assine et al., 1998). Talvez o Arco de Assunção ainda não estivesse bem desenvolvido ainda no Devoniano inicial. Evidências paleontológicas em favor disso é a presença de elementos da fauna do Devoniano da Bolívia no Devoniano da borda noroeste como comentado por Caster (1947a) para o Ribeirão dos Cavalos e por Boucot e Caster (1984), estes últimos citando Scaphiocoelia cf. S. boliviensis para o município de Rio Verde de Mato Grosso (um típico fóssil do Devoniano inferior da Bolívia e outras locais da América do Sul). Isso demonstra uma franca comunicação neste momento com o mar boliviano, possivelmente via o Paraguai. É importante lembrar que Siemiradzky (1898, apud Boucot e Caster, 1984) cita um exemplar de
Scaphiocoelia para o Devoniano inicial do Paraguai.

As marcas de onda encontradas nos arenitos do topo da Formação Ponta Grossa na região de Rio Negro e também em Rio Verde, área mais ao sul de ocorrência no estado, apresentam direções de crista e consequente linha de costa NW-SE (MS05, MS14, MS17, MS18, MS24 e MS57) ou até mesmo W-E (MS54), evidenciando novamente a presença deste alto estrutural atuando mais fortemente apenas a partir do final da Unidade II da Formação Ponta Grossa no estado.

Outra questão importante é que nas áreas ao norte do Devoniano no estado este conjunto de tempestitos e fácies de praia, com águas mais rasas com marcas de onda são menos comuns. Na seção do Rio Taquari (Fig. 5) não ocorrem as espessas camadas de tempestitos da parte superior da seção em Rio Negro (Fig. 3) e Rio Verde (Fig. 4), por exemplo. Mesmo assim, há um aumento da granulação do sedimento em direção ao topo a partir da metade da seção, que passa a ser composta de arenitos em sua maioria, inclusive com um afloramento, próximo ao topo da parte emsiana da seção, apresentando abundantes cristais de cianita (MS67, identificação de Fabiano Faulstich), o que poderia indicar mudanças na área fonte dos sedimentos que mais uma vez poderiam estar relacionadas ao tectonismo singenético.

É importante comentar que tectonismo no Emsiano médio também parece estar atuando na borda leste como evidencia o hiato deposicional confirmado em diversos trabalhos (e.g. Ghran et al., 2012), ou mesmo pela ausência de Zoophycos a partir do Eifeliano, que pode ser uma resposta à restrição da bacia devido ao tectonismo (Sedorko et al., 2019).

\section{CONSIDERAÇÕES FINAIS}

Este trabalho atualiza os mapas de distribuição dos estratos devonianos da Bacia do Paraná no estado de Mato Grosso do Sul, listando também os trabalhos de 
cunho paleontológico desenvolvidos na região. Recentes trabalhos de campo e o levantamento bibliográfico evidenciam a possibilidade de ter existido um tectonismo concomitante à deposição da Formação Ponta Grossa (Grupo Chapada II inferior), principalmente para o topo da unidade, corroborada por um contexto progradacional seguido de um hiato deposicional durante o Emsiano médio ao final do Eifeliano na área. $\mathrm{O}$ soerguimento do Arco de Campo Grande durante este momento talvez tenha sido responsável pela magnitude da regressão na região e pode estar associado a uma reativação tectônica ao final do ciclo Cordilherano (Orogenia Oclóica), relacionada ao choque do microcontinente Chilenia. É importante comentar que tectonismo no Emsiano médio também parece estar atuando na borda leste como evidencia o hiato deposicional confirmado em diversos trabalhos de cunho palinológico ou mesmo icnológico, pela ausência de Zoophycos a partir do Eifeliano, que pode ser uma resposta à restrição da bacia (devido ao tectonismo). Todas estas evidências, aliada a presença de uma fauna malvinocáfrica típica no Pragiano-Emsiano inicial da borda leste no Mato Grosso do Sul, parecem demonstrar que o soerguimento do Arco de Campo Grande, e consequentemente uma eficiente compartimentazilação da Bacia do Paraná, deveria ter ocorrido somente a partir do Emsiano médio a tardio.

\section{Agradecimentos}

Os autores agradecem a Fundação Carlos Chagas de Apoio a Pesquisa do Estado do Rio de Janeiro (FAPERJ E26/200.110/2019) e ao Conselho Nacional de Desenvolvimento Científico e Tecnológico (CNPq 474954/2013-4; CNPq 159548/2018-7) pelo suporte financeiro. Agradecem ao geólogo Felipe Gripp V. de M. Guerra pela elaboração dos mapas. Agradecem também aos demais integrantes do Grupo de Pesquisa do CNPq "Grupo Palaios: paleontologia estratigráfica", na figura do líder Élvio P. Bosetti, pelo auxílio no campo e sugestões.

\section{REFERENCIAS.}

Aguiar A.P.O. 2004. Estratigrafia de alta resolução aplicada ao intervalo Praguiano da região norte da Bacia do Paraná, com base em dados sedimentológicos, geoquímicos e paleoicnológicos. Dissertação de Mestrado, Departamento de pósgraduação, Universidade do Estado do Rio de Janeiro, 96 p.

Almeida F.F.M. 1948. Contribuição à geologia dos estados de Goiás e Mato Grosso. Notas Preliminares e Estudos, DGM, 46, 1-17.

Almeida F.F.M. 1954. Geologia do centroleste Mato-grossense. Boletim da Divisão de Geologia e Mineralogia, 150, 1-97.

Álvarez J., Mpodozis C., Arriagada C., Astini R., Morata D., Salazar E., Valencia V.A., Vervoort J.D. 2011. Detrital zircons from late Paleozoic accretionary complexes in northcentral Chile (28_e32_S): Possible fingerprints of the Chilenia terrane. Journal of South American Earth Sciences, 32, 460-476.

Amaral Filho Z.P. 1989. Macrozoneamento Geoambiental do Estado de Mato Grosso do Sul. Relatório, Campo Grande: Governo do Estado de Mato Grosso do Sul, 140 p.

Ammon L.V. 1893. Devonische Versteinerungen Von Lagoinha in Matto Grosso (Brasilien). Gesells. F. Erdk. Zu Berlin, Zeits., B. XXVIII, 339-353.

Andrade S.M. 1988. Distribuição regional dos membros Inferior, Médio e Superior da Formação Ponta Grossa e a semelhança litológica do membro médio com a Formação Aquidauana no flanco nordeste da Bacia do 
Paraná. In: Congresso Brasileiro de Geologia, Belém, Pará, 35, 2, 869878.

Andrade S.M., Camarço P.E.N. 1978. Mapeamento Geológico a Leste das Cidades de Iporá-Amorinópolis. Relatório Final da Nuclebrás, Goiânia, 32 p.

Andrade S.M., Camarço P.E.N. 1980. Estratigrafia dos sedimentos devonianos do flanco nordeste da Bacia do Paraná. Congresso Brasileiro de Geologia, 31, 5, 28282834.

Araújo H.J.T., Santos Neto A., Trindade C.A.H., Pinto J.C.A., Montalvão, R.M.G., Dourado T.D.C., Palmeira R.C.B., Tassinari C.C.G. 1982. Geologia. In: Projeto RADAMBRASIL: levantamento de recursos naturais - Folha SF.21, 28, 23-124.

Assine M.L. 1996. Aspectos da estratigrafia de sequiências pré-carboníferas da Bacia do Paraná no Brasil. Tese de Doutorado, Programa de PósGraduação em Geologia, Universidade de São Paulo, 207 p.

Assine M.L. 2001. O ciclo Devoniano na Bacia do Paraná e correlação com outras Bacias Gondwanicas. In: Melo J.H.G., Terra G.J.S. (eds.). Correlação de sequências paleozóicas Sulamericanas. Ciência-TécnicaPetróleo, Seção Exploração de Petróleo, 20, 55-62.

Becker-Kerber B., Osés G.L., Curado J.F., Rizzutto M.A., Rudnitzki I.D., Romero G.R., Onary-Alves S.Y., Morais L., Benini V.G., Galante D., Rodrigues F., Buck P.V., Rangel E.C., Ghilardi R.P., Pacheco M.L.A.F. 2017. Shell mineralogy influences fossilization processes - a diagenetic model for a malvinokaffric devonian biota, Palaeos, no prelo.

Benini V.G., Kerber B.B., Silva E.F., Silva T.A., Pacheco M.L.A.F. 2016. Considerações sobre a taxonomia dos
Discinidae (Brachiopoda:

Linguliformea) do Devoniano da Bacia do Paraná, Mato Grosso do Sul, Brasil. Paleontologia em Destaque, 69, p. 66.

Bergamaschi S. 1999. Análise estratigráfica do Siluro-Devoniano (formações Furnas e Ponta Grossa da Sub-bacia de Apucarana), Bacia do Paraná, Brasil. Tese de Doutorado, Programa de Pós-Graduação em Geologia, Universidade de São Paulo, 167 p.

Bergamaschi S., Pereira E. 2001. Caracterização de sequências deposicionais de $3^{\mathrm{a}}$ ordem para $\mathrm{o}$ Siluro-Devoniano na sub-bacia de Apucarana, Bacia do Paraná, Brasil. Ciência-Técnica-Petróleo, Seção Exploração de Petróleo, 20, 63-72.

Beurlen K. 1956. A geologia pósalgonquiana do sul do Estado do Mato Grosso. Boletim da Divisão de Geologia e Mineralogia, 163, 1-137.

Borghi, L. \& Fernandes, A. C. S., 2001. A new tracefossil from the Devonian of the Paraná State (ParanáBasin), Brazil. Boletim do Museu Nacional, Nova Série, Geologia (58):1-12.

Bosetti E.P. 1989. Paleontologia do Lingulida (Brachiopoda-: Inarticulata) da Formação Ponta Grossa, Devoniano, Bacia do Paraná, Brasil. Dissertação de Mestrado, Curso de Pós-graduação em Geociências, Universidade Federal do Rio Grande do Sul, 136 p.

Bosetti E.P. 2004. Tafonomia de alta resolução das fácies de offshore da sucessão devoniana na região de Ponta Grossa, Paraná, Brasil. Tese de Doutorado, Universidade Federal do Rio Grande do Sul-UFRGS, Programa de Pós-graduação em Geociências, 137 p.

Bosetti E.P., Horodyski R.S., Zabini C., Matsumura W.M.K., Penteado A.C. 2010. Ocorrência de fenótipos subnormais no limite Neoeifeliano/Eogivetiano, Tibagi, estado do Paraná: implicações 
tafonômicas e paleossinecológicas. Boletim do Museu Paraense Emílio Goeldi, série Ciências Naturais, 5(2), 135-149.

Bosetti E.P., Grahn Y., Horodyski R.S., Mauller P.M., Breuer P., Zabini C. 2011. An earliest Givetian "Lilliput Effect" in the Paraná Basin, and the collapse of the Malvinokaffric shelly fauna. Paläontologische Zeitschrift, $85,49-65$.

Bosetti E.P., Grahn Y., Horodyski R.S., Mauller P.M., Breuer P. 2012. The first recorded decline of the Malvinokaffric Devonian fauna in the Paraná Basin (southern Brazil) and its cause, taphonomic and fossil evidences. Journal of South American Earth Sciences, 37, 1-14.

Bosetti E.P., Sedorko D., Mysinski Junior L.J., Scheffler S.M., Silva R.C. 2015. Descrição preliminar de novo afloramento da Formação Ponta Grossa no Mato Grosso do Sul (Bacia do Paraná Devoniano) distribuição taxonômica, tafonômica e icnológica. In: Encontro Regional de Paleontologia - PALEO PR/SC, 2015, $1-10$.

Boucot A.J., Caster K.E. 1984. First occurrence of Scaphiocoelia (Brachiopoda, Terebratulida) in the Early Devonian of the Paraná Basin, Brazil. Journal of Paleontology, 58(6), 1354-1359.

Carbonaro F.A., Ghilardi R.P. 2016. Fósseis do Devoniano de Goiás, Brasil (Sub-bacia Alto Garças, Bacia do Paraná). Papéis Avulsos de Zoologia, MZUSP, 56(11), 135-149.

Comniskey J.C. 2011. Paleontologia dos Discinidae (Brachiopoda: Linguliformea) da sucessão devoniana da Bacia do Paraná, Estado do Paraná, Brasil: Revisão sistemática, distribuição geográfica e estratigráfica. Dissertação de Mestrado, Universidade Estadual de Ponta Grossa, Programa de PósGraduação em Geografia, 182 p.
Comniskey J.C. 2016. Revisão sistemática, tafonomia, distribuição geográfica e estratigráfica da classe Tentaculitoidea no Devoniano brasileiro. Tese de Doutorado, Universidade de São Paul, Ffclrp Departamento de Biologia, Programa de Pós-Graduação em Biologia Comparada, $152 \mathrm{p}$.

Carvalho M.G.P., Melo J.H.G., Quadro L.P. 1987. Trilobitas Devonianos do flanco noroeste da Bacia do Paraná. In: Congresso Brasileiro de Paleontologia, 10, p. 36.

Carvalho M.A., Trindade V., Sombra L., Scheffler S.M. 2016. Análise de palinofácies preliminar da Borda Noroeste da Bacia do Paraná (Devoniano): Inferências Paleoambientais. In: Congresso Brasileiro de Geologia, 48, online.

Caster K.E. 1947a. Exedição Geológica em Goiás e Mato Grosso. Nota apresentada em agosto de 1947 à Academia Brasileira de Ciências e publicada em Mineração e Metalurgia, 12(69), 126-127.

Caster K.E. 1947b. Devonian System in Goias and Mato Grosso, Brazil. (Abstract) Geological Society of America, Bulletin, 58, p. 1172.

Caster K.E. 1952. Stratigraphic and Paleontologic Data relevant to the Problem of Afro-American ligation during the Paleozoic and Mesozoic. Bulletin of the American Museu of Natural History, 99, 105-158.

Caster K.E. 1954a. A new Carpoid Echinoderm from the Paraná Devonian. Anais da Academia Brasileira de Ciências, 26(1), 123147.

Caster K.E. 1954b. A Devonian Placocystoid Echinoderm from Paraná, Brazil. In: Lange F.W. (ed.). Paleontologia do Paraná, Curitiba, Comissão de Comemorações do Centenário do Paraná, p. 137-148.

Caster K.E., Mendes J.C. 1952. Comparação Geologica entre a 
America do Sul e a Africa do Sul, por A. L. DuToit (tradução com comentários do autor e dos editores). Instituto brasileiro de Geografia e Estatística, Serv. Graf., 179p.

Ciguel J.H.G. 1989. Bioestratigrafia dos Tentaculitoidea no flanco oriental da Bacia do Paraná e sua ocorrência na América do Sul (OrdovicianoDevoniano). Dissertação de Mestrado, Instituto de Geociências, Universidade de São Paulo, 237 p.

Clarke J.M. 1913. Fósseis Devonianos do

Paraná. Monografias, Serviço Geológico e Mineralógico do Brasil, $353 \mathrm{p}$.

Corrêa J.A., Correia Filho F.C.L., Scislewski G., Neto C., Cavallon L.A., Cerqueira N.L.S., Nogueira V.L. 1976. Projeto Bodoquena: relatório final. Goiânia: CPRM/DNPM, 73 p.

Corrêa J.A., Correia Filho F.C.L., Scislewski G., Neto C., Cavallon L.A., Cerqueira N.L.S., Nogueira V.L. 1979. Projeto Bodoquena: Geologia das regiões centro e oeste de Mato Grosso do Sul. CPRM/DNPM, $111 \mathrm{p}$.

CPRM. 2004. Carta Geológica ao Milionésimo do Brasil. Departamento Nacional de Produção Mineral/Companhia de Pesquisa em Recursos Minerais, CD-ROOM, folhas SE. 21 - Corumbá e SF. 21 Campo Grande.

Daemon R.F., Quadros L.P., Silva L.C. 1967. Devonian palynology and biostratigraphy of the Paraná Basin. In: Bigarella J.J. (ed.). Problems in brazilian Devonian geology. Boletim Paranaense de Geociências, 21/22, p. 99-132.

Del'Arco J., Silva R.H., Tarapanoff I., Freire F.A., Pereira L.G.M., Souza S.L., Luz D.S., Palmeira R.C.B., Tassinari C.C.G. 1982. Geologia. In: Projeto RADAMBRASIL: levantamento de recursos naturais Folha SE.21, Corumbá, 27, p. 25-160.
Derby O.A. 1878. A Geologia da Região Diamantífera da Província do Paraná. Arquivos do Museu Nacional, 3, 8996

Derby O.A. 1890. Nota sobre a Geologia e Paleontologia de Matto-Grosso. Archivos do Museu Nacional, 9, 5988.

Dino R. 1999. Palynostratigraphy of the Silurian and Devonian sequence of the Paraná Basin, Brazil. In: Ordovician - Devonian Palynostratigraphy In Western Gondwana: Update, Problems And Perspectives, 1999. Resumos expandidos, Rio de Janeiro, UERJ, p. 27-61.

Erichsen A.I., Lofgreen A. 1940. Geologia de Goiaz a Cuiabá. Departamento Nacional de Produção Mineral, Divisão de Geologia e Mineralogia, Boletim 102, 40p.

Evans J.W. 1894. The Geology of Matto Grosso (particularly the region drained by the Upper Paraguay). Quarterly Journal of the Geological Society of London, 50(2), 85-104.

Ferreira R.S., Scheffler S.M. 2015. Discinideos da Formação Ponta Grossa (Devoniano Inferior), do estado do Mato Grosso do Sul, Brasil. In: Jornada de Iniciação Científica da UFRJ, 2015, Boletim de resumos, p. $1-1$.

Furtado L., Thele M.C., Rebolo I.F., Cavalcante M., Rizzi C., Barretto I., Pereira L.R., Provase M., Rodrigues J., Becker B., Pacheco M.L.F. 2016. Epibiose em Gidadiscina sp. (Formação de Ponta Grossa, Rio Verde, MS). Paleontologia em Destaque, Boletim Informativo da SBP, 69, p. 67.

Ghilardi R.P. 2004. Tafonomia comparada e paleoecologia dos macroinvertebrados (ênfase em trilobites), da Formação Ponta Grossa (Devoniano, Sub-bacia Apucarana), Estado do Paraná, Brasil. Tese de Doutorado, Instituto de Geociências, 
Curso de Pós-Graduação em Geologia Sedimentar, Universidade de São Paulo, 113 p.

Ghilardi R.P., Scheffler S.M., Carbonaro F.A. 2016. Registro de trilobitas para sedimentos devonianos do Mato Grosso do Sul (Devoniano Inferior, Sub-Bacia Alto Garças). In: Simpósio Brasileiro de Paleoinvertebrados, 3, Boletim de Resumos.

Goncalves C.G., Trindade V., Carvalho M.A., Araujo L.R., Scheffler S.M. 2018. Registro Palinológico Preliminar de Escolecodontes nas Seções Devonianas da Borda Noroeste da Bacia do Paraná, Mato Grosso do Sul. In: IV Simpósio Brasileiro de Paleoinvertebrados, 4, Paleontologia em Destaque, volume especial, Boletim de resumos, 1, p. 87-88.

Grahn Y., Pereira E., Bergamaschi S. 2000. Silurian and Lower Devonian chitinozoan biostratigraphy of the Paraná Basin in Brazil and Paraguay. Palynology, 24, 143-172.

Grahn Y., Pereira E., Bergamaschi S. 2002. Middle and Upper Devonian chitinozoan biostratigraphy of the Paraná Basin in Brazil and Paraguay. Palynology, 26, 135-165.

Grahn Y., Mauller P.M., Pereira E., Loboziak S. 2010. Palynostratigraphy of the Chapada Group and its significance in the Devonian stratigraphy of the Paraná Basin, south Brazil. Journal of South Americam Earth Sciences, 29, 354370.

Grahn Y., Mauller P.M., Bergamaschi S., Bosetti E.P. 2013. Palynology and sequence stratigraphy of three Devonian rock units in the Apucarana Sub-basin (Paraná Basin, south Brazil): Additional data and correlation. Review of Palaeobotany and Palynology, 198, 27-44.

Grahn Y., Horodyski R.S., Mendlowicz Mauller P., Bosetti E.P., Ghilardi R.P., Carbonaro F.A. 2016. A marine connection between Parnaíba and Paraná Basins during the Eifelian/Givetian transition: review and new data. Revista Brasileira de Paleontologia, 19(3), 357-366.

Horodyski R.S. 2010. Tafonomia dos invertebrados fósseis na sequência eifeliana-frasniana da sucessão devoniana da Subbacia de Apucarana, Bacia do Paraná, Tibagi - Pr, Brasil. Dissertação de Mestrado, Programa de Pós-graduação em Geociências, Instituto de Geociências, Universidade Federal do Rio Grande do Sul, 82 p.

Horodyski R.S. 2014. Análise tafonômica, bioestratigráfica e paleoambiental dos invertebrados marinhos da região de Tibagi-Pr (Devoniano Inferior e Médio da Bacia do Paraná). Tese de Doutorado, Universidade Federal do Rio Grande do Sul, Instituto de Geociências, Programa de PósGraduação em Geociências, 204 p.

Isaacson, P. E. A Reassessment of Andean Mid-Paleozoic biogeography. In: CONGRESSO

LATINOAMERICANO DE PALEONTOLOGIA, 2, 1981, Porto Alegre. Anais... Porto Alegre, Sociedade Brasileira de Paleontologia, pp. 75-78, 1981.

Isaacson, P. E. Devonian biogeography and paleogeography of western Gondwana: malvinokaffric endemism, faunal migration, and organic microfossil provincialism. In: SIMPÓSIO SUL AMERICANO DO SILURO-DEVONIANO,

1: Estratigrafia e Paleontologia, 1996, Ponta Grossa. Anais... Ponta Grossa, Universidade Federal do Paraná, Universidade Estadual de Ponta Grossa, pp. 193-218, 1996. ISAACSON, P. E., PERRY, D. G. Biogeography and morphological conservatism of Tropidoleptus (Brachiopoda, Orthida) during the the Devonian. Journal of Paleontology, v. 51, n. 6, pp. 1108-1122, 1977. 
Isaacson, P. E., Sablock, P. E. Devonian paleogeography and palaeobiogeography of the Central Andes. Memoir Geological Society of london, v. 12, pp. 431-435, 1990.

Isaacson, P. E., Martinez, E. D. Evolução paleogeografica del Paleozoico Medio y Superior de los Andes centrales $\left(14^{\circ}\right.$ a $\left.18^{\circ} \mathrm{S}\right)$ en Bolivia: evidencia del desplazmiento latitudinal de una cuenca de antepais. revista técnica de $\mathrm{PFB}$, v. 15, n. 3-4, pp. 265-282, 1994.

Kotzian C.B., Marchioro A. 1997. Gastrópodes (Mollusca) Devonianos da Formação Ponta Grossa no Estado do Paraná (Bacia do Paraná): gêneros Ptomatis Clarke, 1899, Pleurotomaria Defrance, 1826 e Platyceras Conrad, 1840. Revista Ciência e Natura, 19, 77-117.

Kozloswki R. 1913. Fossiles Dévoniens de l'Etat de Paraná (Brésil). Ann. Paléont., 8, 105-123.

Lacerda Filho J.V., Brito R.S.C., Silva M.G., Oliveira C. C., Moreton L.C., Martins E.G., Lopes R.C., Lima T.M., Larizzatti, J.H., Valente, C.R., 2006. Geologia e recursos minerais do Estado de Mato Grosso do Sul. Programa Geologia do Brasil (Convênio CPRM/SICME): Integração, Atualização e Difusão de Dados da Geologia do Brasil, 121 p.

Lange F.W. 1943. Novos fósseis Devonianos do Paraná. Arquivos do Museu Paranaense, 3(8), 215-231.

Lange F.W. 1954. Paleontologia do Paraná. In: Lange F. W. (ed.) Paleontologia do Paraná, Comissão de Comemorações do Centenário do Paraná, 1-105.

Lange F.W. 1967. Biostratigraphic subdivision and correlation of the Devonian in the Paraná Basin. In: Bigarella J.J. (ed.). Problems in brazilian Devonian geology. Boletim Paranaense de Geociências, 21/22, 63-98.
Lange F.W., Petri S. 1967. The Devonian of the Paraná Basin. In: Bigarella J.J. (ed.). Problems in brazilian Devonian geology. Boletim Paranaense de Geociências, 21/22, 5-55.

Leme J. 2006. Título: Análise cladística dos Conulatae (Cambriano-Triássico): caracterizando e definindo o escopo de um enigmático grupo de cnidários extintos. Tese de Doutorado, Universidade de São Paulo-USP, Programa de Pós-Graduação Paleontologia e Estratigrafia, 107 p.

Leme J., Rodrigues S., Simões M., Iten H.V. 2004. Sistemática dos Conulários (Cnidaria) da Formação Ponta Grossa (Devoniano), do Estado do Paraná, Bacia do Paraná, Brasil. Revista Brasileira de Paleontologia, Suplemento, 7(2), 213-222.

Melo J.H.G. 1985. A Província Malvinocáfrica no Devoniano do Brasil: estado atual dos conhecimentos. Dissertação de Mestrado, Departamento de Geologia, Instituto de Geociências, Universidade Federal do Rio de Janeiro, $890 \mathrm{p}$.

Melo J.H.G. 1988. The Malvinokaffric Realm in the Devonian of Brazil. In: McMillam N.J., Embry A.F., Glass D.J. (eds.). International Symposium on the Devonian System, 2, p. 669703.

Melo J.H.G., Loboziak S. 2003. DevonianEarly Caboniferous biostratigraphy of the Amazon Basin, Northern Brazil. Review of Palaeobotany and Palynology, 124, 131-202.

Mendlowicz Mauller P. 2007. Bioestratigrafia do Devoniano da Bacia do Paraná - Brasil, com ênfase na Sub-Bacia de Alto Garças. Tese de Doutorado, Universidade do Estado do Rio de Janeiro, Faculdade de Geologia, 191 p.

Mendlowicz Mauller P., Grahn Y., Cardoso T.R.M. 2009. Palynostratigraphy from the Lower Devonian of the Paraná Basin, South Brazil, and a 
revision of contemporary Chitinozoan biozones from Western Gondwana. Stratigraphy, 6(4), 313332.

Milani E.J., Ramos V.A. 1998. Orogenias paleozóicas no domínio sul-ocidental do Gondwana e os ciclos de subsidência da Bacia do Paraná. Revista Brasileira de Geociências, 28, 473-484.

Milani E.J., Melo J.H.G., Souza P.A., Fernandes L.A., França A.B. 2007. Bacia do Paraná. Boletim de Geociências da Petrobrás, 15(2), 265287.

Moraes Rego L.F. 1940. O Sistema Devoniano do Brasil. Anuário da Escola Politécnica da Universidade de São Paulo para o ano de 1938, VII ano, $2^{\mathrm{a}}$ série, 127-224.

Morsch S.M. 1986. Bivalves (Mollusca) da Formação Ponta Grossa (Bacia do Paraná - Devoniano), Revisão Sistemática. Anais da Academia Brasileira de Ciências, 58, 403-431.

Mori A.S., Leme J. 2016. Systematic revision of Calmoniidae (Trilobita, Phacopida) of the Ponta Grossa Formation (Devonian), Paraná Basin, Apucarana Sub-basin, Brazil. Revista Brasileira de Paleontologia, 19, 167180.

Northfleet A.A., Medeiros R.A., Mülhmann H. 1969. Reavaliação dos dados geológicos da Bacia do Paraná. Boletim Técnico da Petrobrás, 12(3), 291-346.

Oliveira S.F. 1997. Palinologia da seqüência Devoniana da Bacia do Paraná no Brasil, Paraguai e Uruguai: implicações biocronoestratigráficas, paleoambientais e paleogeográficas. Tese de Doutorado, Instituto de Geociências, Universidade de São Paulo, Programa de Pós-graduação em Geologia Sedimentar e Ambiental, $139 \mathrm{p}$.

Oliveira A.I., Leonardos O.H. 1978. Geologia do Brasil, $3^{a}$ ed. Escola
Superior de Agricultura de Mossoró, Coleção Mossoroense, 72, 813 p.

Oliveira M.A.M., Mühlmann H. 1965. Geologia de semi-detalhe da região de Mutum, Jaciara, São Vicente e Chapada dos Guimarães. Ponta Grossa, PETROBRAS-DEBSP, Relatório técnico interno, 300, 62 p.

Oliveira M.A.M., Muhlmann H. 1967. Observations on the geology of Chapada dos Guimarães, Mato Grosso. In: Bigarella, J.J. (ed.), Problems in Brazilian Devonian geology. Curitiba. Boletim Paranaense de Geociências, 21/22, 57-61.

Pereira E. 2000. Evolução tectonosedimentar do intervalo OrdovicianoDevoniano da Bacia do Paraná com ênfase na Sub-Bacia de Alto do Garças e no Paraguai oriental. Tese de Doutorado, Programa de PósGraduação em Geologia Sedimentar, Instituto de Geociências, Universidade de São Paulo, 276 p.

Pereira E., Aguiar A.P.O., Freitas-Brazil F.A., Blazutti D. 2007. Estratigrafia de Alta Resolução e o registro icnofacionlógico. In: Carvalho I.S., Fernandes A.C.S. (eds.). Icnologia. Sociedade Brasileira de Paleontologia, Série Textos, 3, 178 p.

Petri S., Fúlfaro V.J. 1988. Geologia do Brasil: Fanerozóico. $2^{\mathrm{a}}$ ed. T. A. Queiroz/Ed. da Universidade de São Paulo, 9, $631 \mathrm{p}$.

Rapela C.W. 2000. The Sierras Pampeanas of Argentina: Paleozoic building of the Southern proto-Andes. In: Cordani U.G., Milani E.J., Thomaz Filho A., Campos D.A. (eds.). Tectonic Evolution of South America, International Geological Congress, 31, 381-388.

Rocha-Campos A.C., Farjallat E.S. 1966. Sôbre a extensão da Formação Botucatu na região meridional de Mato Grosso. Boletim da Sociedade Brasileira de Geologia, 15(4), 93-105. 
Rodrigues S.C. 2002. Tafonomia comparada dos conulatae Collins et al 2000, Formação Ponta Grossa, Devoniano (? LochkovianoFrasniano) Bacia do Paraná: Implicações paleoautoecológicas e Paleoambientais. Dissertação de Mestrado, Instituto de Geociências, Curso de Pós-Graduação em Geologia Sedimentar, Universidade de São Paulo, 100 p.

Rodrigues S.C., Simões M.G., Leme J.M. 2003. Tafonomia comparada dos Conulatae (Cnidaria), Formação Ponta Grossa (Devoniano), Bacia do Paraná. Revista Brasileira de Geociências, 33, 1-10.

Sausen T.M., Kux H. 1982. Mapeamento morfoestrutural da região de Corguinho, Rochedo, Rio Negro e São Gabriel do Oeste (MS), através de dados MSS/RBV do Landsat. In: Simpósio Brasileiro de Sensoriamento Remoto, 2, 67-76.

Scheffler S.M. 2007. Equinodermas da Formação Ponta Grossa (Devoniano:Bacia do Paraná): grupos conhecidos e perspectivas futuras. In: Carvalho I.S., Cassab R.C.T., Schwanke C., Carvalho M.A., Fernandes A.C.S., Rodrigues M.A.C., Carvalho M.S.S., Arai M., Oliveira M.E.Q. (org.). Paleontologia: cenários da vida, Editora Interciência Ltda., 1, 157-166.

Scheffler S.M. 2015. Stalked echinoderms of the Brazilian Devonian and their palaeobiogeographical affinities. Boletim do Museu Paraense Emílio Goeldi, Ciências Naturais, 10, 63-81.

Scheffler S.M., Fernandes A.C.S. 2007a. Crinoidea da Formação Ponta Grossa (Devoniano, Bacia do Paraná), Brasil. Arquivos do Museu Nacional, 65, 8398.

Scheffler S.M., Fernandes A.C.S. 2007b. Blastoidea da Formação Ponta Grossa (Devoniano, Bacia do Paraná), Estado do Paraná, Brasil. Arquivos do Museu Nacional, 65, 99-112.
Scheffler S.M., Martins G.R., Kashimoto E.M., Oliveira A.M. 2010. A paleontologia no estado do Mato Grosso Do Sul: fósseis e afloramentos conhecidos. Brazilian Geographical Journal: Geosciences and Humanities research medium, 1, 65-99.

Scheffler S.M., Fernandes A.C.S.F., Fonseca V.M.M. 2013. Alguns Crinoides da Formação Ponta Grossa e suas afinidades paleobiogeográficas (Devoniano Inferior, Bacia do Paraná, Brasil). Terr@ Plural (UEPG. Online), 7, 85-114.

Scheffler S.M., Silva R.C., Fernandes A.C.S. 2015. Primeira ocorrência de espícula de Porifera (Hexactinellida) na Formação Ponta Grossa (Grupo Chapada II), Estado do Mato Grosso do Sul, BRASIL. In: Congresso Brasileiro de Paleontologia, 24, 170171.

Scheffler S.M., Silva R.C. 2014. Ocorrência de diversa fauna Malvinocáfrica (Devoniano Inferior) no estado do Mato Grosso do Sul, Brasil. In: Simpósio Brasileiro de Paleoinvertebrados, 2, 132-132.

Scheffler S.M., Silva R.C. 2015a. O Devoniano no Estado do Mato Grosso do Sul, Brasil: nova área de ocorrência geológica e abundante presença de típica fauna malvinocáfrica. In: Congresso Brasileiro de Paleontologia, 24, 1461.

Scheffler S.M., Silva R.C. 2015b. O Devoniano no Estado do Mato Grosso do Sul, Brasil: nova área de distribuição e abundante presença de típica fauna malvinocáfrica. In: Encontro Regional de Paleontologia PALEO RJ/ES, 2015, Boletim de Resumos, 1-1.

Scheffler S.M. 2016. Crinóides (Echinodermata) na Formação Ponta Grossa em Mato Grosso do Sul (Grupo Chapada II, Devoniano Inferior da Bacia do Paraná). In: 
Simpósio Brasileiro de Paleoinvertebrados, 3, CDROM.

Schneider R.L., Muhlmann H., Tommasi E., Medeiros R.A., Daemon R.F., Nogueira A.A. 1974. Revisão estratigráfica da Bacia do Paraná. In: Congresso Brasileiro de Geologia, 28, 41-65.

Sedorko D., Fallgatter C., Scheffler S.M., Silva R.C., Bosetti E.P. 2016. Icnofábricas em turbiditos do Devoniano da Bacia do Paraná, Subbacia Alto Garças: implicações paleoambientais. In: Simpósio Brasileiro de Paleoinvertebrados, 3, CDROM.

Sedorko D., Netto R.G., Savrda C.E., Assine M.L., Tognoli F.M.W. 2017. Chronostratigraphy and environment of Furnas Formation by trace fossil analysis: Calibrating the lower Paleozoic Gondwana realm in the Paraná Basin (Brazil). Palaeogeography, Palaeoclimatology, Palaeoecology 487, 307-320. http://dx.doi.org/10.1016/j.palaeo.20 17.09.016

Sedorko D., Netto R.G., Savrda C.E. 2018a. Ichnology applied to sequence stratigraphic analysis of SiluroDevonian mud-dominated shelf deposits, Paraná Basin, Brazil. Journal of South American Earth Sciences, 83, 81-95. https://doi.org/10.1016/j.jsames.2018 .02 .008

Sedorko D., Bosetti E.P., Netto R.G. 2018b. An integrative ichnological and taphonomic approach in a transgressive-regressive cycle: a case study from Devonian of Paraná Basin, Brazil. Lethaia, 51, 15-34. DOI 10.1111/let.12219

Sedorko D., Netto R.G., Horodyski R.S. 2018c. A Zoophycos carnival in Devonian beds: Paleoecological, paleobiological, sedimentological, and paleobiogeographic insights. Palaeogeography, Palaeoclimatology, Palaeoecology, 507, 188-200. https://doi.org/10.1016/j.palaeo.2018 .07.016.

Sedorko D., Bosetti E.P., Ghilardi R.P., Myszynski-Júnior L.J., Silva R.C., Scheffler S.M. 2018d. Paleoenvironments of a regressive Devonian section from Paraná Basin (Mato Grosso do Sul state) by integration of ichnologic, taphonomic and sedimentologic analyses. Brazilian Journal of Geolology, 48(4), 805-820. https://doi.org/10.1590/23174889201820180021.

Sedorko D., Matsumura W.M.K., Bosetti E., Silva R.C., Scheffler S.M., Mauller P.M. 2018e. Dense Chondrites-Zoophycos Ichnofabric Associated to Land Plants in Alto Garças Sub-Basin (Early Devonian). In: Simpósio Brasileiro de Paleoinvertebrados, 4, 36-37.

Sedorko D., Netto R.G., Horodyski R.S. 2019. Tracking Silurian-Devonian events and paleobathymetric curves by ichnologic and taphonomic analyzes in the southwestern Gondwana. Global and Planetary Change, 179, 43-56. https://doi.org/10.1016/j.gloplacha.2 019.05 .007

Silva R.C., Scheffler S.M., Dominato V.H. 2014. Novos registros de icnofósseis devonianos no estado do Mato Grosso do Sul, Brasil. In: Simpósio Brasileiro de Paleoinvertebrados, 2, 135-135.

Silva R.C., Scheffler S.M. 2015a. Icnofósseis de invertebrados devonianos na Formação Ponta Grossa (Grupo Chapada II, Bacia do Paraná) no Mato Grosso do Sul, Brasil. In: Congresso Brasileiro de Paleontologia, 24, 163-163.

Silva R.C., Scheffler S.M. 2015. Icnofósseis de invertebrados da Formação Ponta Grossa (Devoniano, Bacia do Paraná) no Mato Grosso do Sul, Brasil. In: Encontro Regional de Paleontologia - PALEO RJ/ES, 2015, Boletim de Resumos, p. 1-1. 
Silva M.B., Comniskey J.C., Scheffler S.M. 2016. Os Discinideos do Devoniano, na Sub-bacia de Alto Garças (Grupo Chapada, Mato Grosso do Sul), Brasil. In: Encontro Regional de Paleontologia - PALEO RJ/ES, 2016, Livro de Resumos, p. 85-85.

Silva M.B., Comniskey J.C., Scheffler S.M. 2017. Novo registro de Rugadiscina (Família Discinidae), Devoniano da Bacia do Paraná, Mato Grosso do Sul. In: Congresso Brasileiro de Paleontologia, 25, 318-318.

Silva M.B., Scheffler S.M., Comniskey J.C. 2018. Os discinoideos do Devoniano, na Sub-Bacia de Alto Garças (Grupo Chapada, Mato Grosso do Sul), Brasil. In: Simpósio Brasileiro de Paleoinvertebrados, 4, p. 40.

Simões M.G., Sales A.M.F., Ghilardi R.P., Holz M., Rodrigues S.C., Leme J.P. 2002. Assinaturas tafonômicas como marcadoras de limites de parasequencias em offshore settings: Um exemplo do Devoniano, Bacia do Paraná, Brasil. Congresso Brasileiro de Geologia, 41, Anais de Congresso.

Simões M.G., Rodrigues S.C., Leme J.M., Iten H.V. 2003. Some Middle Paleozoic conulariids (Cnidaria) as possible examples of taphonomic artifacts. Journal of Taphonomy, 1, 165-186.

Smith H.H. 1883. Discovery of Paleozoic rocks in Western Brazil. The American Naturalist, 17(11), 11561157.

Souza Jr. J.J., Trindade C.A.H., Tarapanoff I. $\quad 1987 . \quad$ Macrozoneamento geoambiental do Estado do Mato Grosso do Sul. Relatório Temático de Geologia, Secretaria de Planejamento da Presidência da República, Fundação Instituto Brasileiro de Geografia e Estatística, Convênio IBGE/SEPLAN-MS, Goiânia, 200 p.

Souza M.S.P., Mendlowicz Mauller P., Cardoso T.R., Rodrigues R., Pereira E. 2013. Caracterização Geoquímica e Bioestratigráfica das Superfícies de
Inundação Marinha da Seção MesoNeodevoniana, na Região de Dom Aquino (MT), Noroeste da Bacia do Paraná, Brasil. Anuário do Instituto de Geociências, 36(1), 15-25.

Torsvik T. H. \& Cocks L. R. M. 2013. Gondwana from top to base in space and time. Gondwana Research, 24(3-4): 999-1030.

Trindade V., Sombra L., Carvalho M.A., Scheffler S.M., Goncalves C.G. 2016. Análise de palinofácies preliminar da borda noroeste da Bacia do Paraná (Devoniano): inferências paleoambientais. In: Encontro Regional de Paleontologia - PALEO RJ/ES, 2016, 93-93.

Trindade V., Gonçalves C.G., Carvalho M.A., Scheffler S.M., Mauller P.M. 2017. Palinofácies e paleoambiente do Devoniano da Bacia do Paraná (borda noroeste, Mato Grosso do Sul). In: Congresso Brasileiro de Paleontologia, 25, 350-350.

Vogel P. 1893. Viagens a Mato Grosso (1887/88) (Segunda Expedição ao Xingu). Traduzido por Krähenbühl, M.A. 2010. Revista de História, 2(3), 173-205, do orginal alemão: Vogel P. 1893. Reisen in Mato Grosso $1887 / 88$ (Zweite Schingu-Expedition). (Hierzu Tafel 3 und 4) in: Zeitschrift der Gesellschaft fur Erdkunde zu Berlin, vol. XXVIII. D. Reimer, Berlin.

Zabini C. 2007. Lingulídeos da sucessão devoniana da Bacia do Paraná, região dos Campos Gerais, Brasil: revisão de conceitos biológicos-ecológicos e análise tafonômica básica. Dissertação de Mestrado, Programa de Pós-graduação em Geociências, Universidade Federal do Rio Grande do Sul, 144 p.

Zabini C., Bosetti E.P., Holz M. 2010. Taphonomy and taphofacies analysis of lingulid brachiopods from Devonian sequences of the Paraná Basin, Brazil. Palaeogeography, 
Palaeoclimatology, Palaeoecology, 292, 44-56.

Willner A., Gerdes A., Massone H.J., Schmidt A., Sudo M., Thomson S., Vujovich G. 2011. The geodynamics of collision of a microplate (Chilenia) in Devonian times deduced by the pressure temperature time evolution within part of a collisional belt (Guarguaraz Complex, WArgentina). Contributions to Mineralogy and Petrology, 162, 303327. doi:10.1007/s00410-010-05988. 